\title{
Tetrahydrofurantetracarboxylic Acid: an Isomerizable Framework-Forming Ligand in Homo- and Heterometallic Complexes with $\mathrm{UO}_{2}{ }^{2+}, \mathrm{Ag}^{+}$and $\mathrm{Pb}^{2+}$
}

\author{
Pierre Thuéry*,† and Jack Harrowfield ${ }^{*,+}$ \\ ${ }^{\dagger}$ NIMBE, CEA, CNRS, Université Paris-Saclay, CEA Saclay, 91191 Gif-sur-Yvette, France \\ ISIS, Université de Strasbourg, 8 allée Gaspard Monge, 67083 Strasbourg, France
}

\begin{abstract}
R^{*}, 3 R^{*}, 4 S^{*}, 5 S^{*}\right)$-Tetrahydrofurantetracarboxylic acid $\left(\mathrm{H}_{4}\right.$ thftc $)$ has been used as a ligand to synthesize five uranyl ion complexes, three of them including additional silver(I) or lead(II) metal cations. The complex $\left[\mathrm{C}\left(\mathrm{NH}_{2}\right)_{3}\right]_{2}\left[\mathrm{UO}_{2}\left(\mathrm{H}_{2} \text { thftc }\right)_{2}\right](\mathbf{1})$, obtained in water at room temperature, is a discrete mononuclear species in which the uranyl cation is bound to the tridentate coordination site (involving the ether oxygen atom and the two adjoining carboxylate groups) of two ligands, and extensive hydrogen bonding is present. All the other complexes were obtained under (solvo)-hydrothermal conditions giving rise to higher degrees of ligand deprotonation. $\left[\left(\mathrm{UO}_{2}\right)_{3}(\mathrm{Hthftc})_{2}\left(\mathrm{H}_{2} \mathrm{O}\right)_{2}\right] \cdot 2 \mathrm{CH}_{3} \mathrm{CN}(2)$ crystallizes as a two-dimensional (2D) network with the $\mathrm{V}_{2} \mathrm{O}_{5}$ topological type, whereas in the heterometallic complex $\left[\left(\mathrm{UO}_{2}\right)_{3} \mathrm{Ag}_{2}(\text { thftc })_{2}\left(\mathrm{H}_{2} \mathrm{O}\right)_{2}\right] \cdot 2 \mathrm{H}_{2} \mathrm{O}(3)$, similar $2 \mathrm{D}$ layers are assembled into a three-dimensional (3D) framework by bridging $\mathrm{Ag}_{2}$ moieties. Lead(II) replaces uranyl in the tridentate coordination site in the two complexes $\left[\mathrm{UO}_{2} \mathrm{~Pb}\left(\right.\right.$ thftc) $\left.\left(\mathrm{H}_{2} \mathrm{O}\right)\right](4)$ and $\left[\mathrm{UO}_{2} \mathrm{~Pb}(\right.$ thftc $\left.)\left(\mathrm{H}_{2} \mathrm{O}\right)_{2}\right] \cdot \mathrm{H}_{2} \mathrm{O}(\mathbf{5})$, and the high connectivity of the ligand, bound to seven metal cations through diverse chelating and bridging interactions, ensures that both are 3D frameworks. Bonding of a uranyl oxo group to either silver(I) or lead(II) is apparent in complexes $\mathbf{3}$ and $\mathbf{5}$. The homometallic complexes $\left[\mathrm{Ag}_{3}(\mathrm{Hthftc})\right](6)$ and $\left[\mathrm{Pb}_{2}(\mathrm{thftc})\left(\mathrm{H}_{2} \mathrm{O}\right)\right]$ (7), devoid of uranyl cations, are both 3D frameworks in which the ligand is bound to 11 or 9 metal cations, respectively. Complex 6 is the single instance in this series in which the ligand, originally in the trans,cis,trans form, has undergone isomerization into the chiral cis,trans,trans $\left(2 R^{*}, 3 S^{*}, 4 S^{*}, 5 S^{*}\right)$ form through a process probably involving an ene-diol intermediate. Only complexes 1, 2 and 4 display intense and well-resolved emission bands under excitation at $420 \mathrm{~nm}$ in the solid state, the uranyl emission of complexes $\mathbf{3}$ and $\mathbf{5}$ being largely quenched.
\end{abstract}




\section{INTRODUCTION}

An appealing ligand with a somewhat flexible conformation and four possible degrees of deprotonation, tetrahydrofurantetracarboxylic acid ( $\mathrm{H}_{4}$ thftc) has not been widely used till now, and virtually all the crystal structures reported for its salts or complexes contain alkali, alkaline-earth, ${ }^{1,2}$ or d-block metal cations. ${ }^{3-13}$ In the f-element series, the complexation of lanthanide ions by $\mathrm{H}_{4}$ thftc was investigated in solution, ${ }^{14,15}$ and the complexes formed were shown to be stronger than those with uranyl ion; ${ }^{15}$ the weak complexation of the latter cation compared with that of transuranic elements was put to use in a solvent extraction process for nuclear waste reprocessing. ${ }^{16}$ However, no crystal structure of a lanthanide or transuranic cation complex with $\mathrm{H}_{4}$ thftc has ever been reported, and, apart from the complexes of the cations cited above, the only crystallographically characterized species are three uranyl ion complexes. ${ }^{17,18}$

In the overwhelming majority of the known structures containing $\mathrm{H}_{4}$ thftc or its anions, either free or complexed, the molecule retains the achiral trans,cis,trans $\left(2 R^{*}, 3 R^{*}, 4 S^{*}, 5 S^{*}\right)$ isomeric form of the single species shown to be present in the commercially available acid. ${ }^{14}$ In principle, six diastereomeric forms are possible and in some early publications ${ }^{3,19}$ evidence for the presence of more than one has been noted. More significantly, in a recent study of zinc(II) complexes, mainly mixed-ligand species, obtained by solvothermal syntheses, clear evidence was obtained for the isomerization of the achiral acid to the chiral $\left(2 R^{*}, 3 S^{*}, 4 S^{*}, 5 S^{*}\right)$ form, isolated in good yield in several complexes. ${ }^{8}$ An acid-dependent inversion process, relatively rapid at the temperature of solvothermal methods and involving an ene-diol intermediate, was suggested to be the cause of this isomerization and such a mechanism could also explain the observation of related isomerization processes in other alicyclic polycarboxylic acids used to prepare metal ion complexes

by solvothermal methods. ${ }^{20-25}$ Thus, under acidic solvothermal conditions, $\mathrm{H}_{4}$ thftc can be regarded 
as being in a dynamic equilibrium involving possibly up to 6 diastereomeric species and thus can be considered as a single-molecule dynamic covalent library,${ }^{26}$ open potentially to selective coordination and amplification of a given isomer depending upon the metal and, as shown in the case of crystalline $\mathrm{Zn}^{\mathrm{II}}$ complexes, ${ }^{8}$ any co-ligands. The present work provides one further example of this selective coordination within a precipitated solid, this resulting from our continuing efforts to characterise the influence of the presence of other heavy metal ions on the structure of uranyl ion/polycarboxylate coordination polymers.

Of the known uranyl ion complexes of $\mathrm{H}_{4}$ thftc, which all contain the $\left(2 R^{*}, 3 R^{*}, 4 S^{*}, 5 S^{*}\right)$ isomer, $\quad[\mathrm{Hpip}]_{6}\left[\mathrm{UO}_{2}(\mathrm{thftc})\right]_{3} \cdot 9 \mathrm{H}_{2} \mathrm{O}$ (where pip is $N$-ethylpiperidine) and $\left[\mathrm{HNEt}_{3}\right]_{8}\left[\mathrm{UO}_{2}(\text { thftc) }]_{4} \cdot 2 \mathrm{MeOH} \cdot 2 \mathrm{H}_{2} \mathrm{O}\right.$ were synthesized in organic solvents (methanol or dimethylsulfoxide) at room temperature, in the presence of an organic base, ${ }^{17}$ both are metallamacrocycles, with three and four metal centres, respectively, in which one uranyl ion is chelated by the two carboxylate groups in the positions 2 and 5 and is also bound to the ether oxygen donor in between (a tridentate coordination site analogous to that of oxydiacetate), and another one is chelated by the carboxylate groups in the positions 3 and 4 (analogous to succinate). Under mild conditions, isomerization of the ligand would not be anticipated but the $\left(2 R^{*}, 3 R^{*}, 4 S^{*}, 5 S^{*}\right)$ configuration is also found in the heterometallic complex $\left[\mathrm{UO}_{2} \mathrm{Cu}\right.$ (thftc)(bipy) $\left.\left(\mathrm{H}_{2} \mathrm{O}\right)\right] \cdot 2 \mathrm{H}_{2} \mathrm{O}$ (bipy $=2,2^{\prime}$-bipyridine), where the tetracarboxylic acid is again fully deprotonated, which was obtained under hydrothermal conditions at a temperature of 180 ${ }^{\circ} \mathrm{C} .{ }^{18}$ This compound crystallizes as a two-dimensional (2D) array with the $\left\{4^{4} \cdot 6^{2}\right\}$ point symbol, in which the $\left[\mathrm{Cu}(\text { bipy })\left(\mathrm{H}_{2} \mathrm{O}\right)\right]^{2+}$ cations have no topological role. The coordination mode here is different from that in the homometallic, molecular species since the copper(II) cation occupies the tridentate coordination site. Such differences between homo- and heterometallic complexes of a given ligand are well-known in general and have been explored in the field of uranyl complexes, ${ }^{27-}$ 
35 although principally with the objective there of increasing the dimensionality of the lattice to generate uranyl-organic frameworks $\left(\mathrm{UOFs}^{36-39}\right)$ and not for the purpose of selecting different ligand isomers. To explore both issues and in continuation of our recent work on heterometallic complexes of 1,3,5-benzenetriacetic acid involving metal ions with very different coordination preferences, ${ }^{40}$ we have now examined the complexes formed by uranyl cations with $\mathrm{H}_{4}$ thftc, mainly in the presence of silver(I) or lead(II) cations under (solvo)-hydrothermal conditions, and we report herein the crystal structures and emission spectra in the solid state of three heterometallic complexes, all of them three-dimensional (3D) frameworks, as well as those of four homometallic complexes, containing either uranyl, silver or lead alone, for comparison purposes. The homometallic $\mathrm{Ag}^{\mathrm{I}}$ complex provides the second example of crystallization of the $\left(2 R^{*}, 3 S^{*}, 4 S^{*}, 5 S^{*}\right)$ isomer of the ligand.

\section{EXPERIMENTAL SECTION}

Syntheses. Caution! Uranium is a radioactive and chemically toxic element, and uraniumcontaining samples must be handled with suitable care and protection.

$\mathrm{UO}_{2}\left(\mathrm{NO}_{3}\right)_{2} \cdot 6 \mathrm{H}_{2} \mathrm{O}$ (depleted uranium, R. P. Normapur, 99\%), $\mathrm{AgNO}_{3}, \mathrm{~Pb}\left(\mathrm{NO}_{3}\right)_{2}$ and $\left[\mathrm{C}\left(\mathrm{NH}_{2}\right)_{3}\right] \mathrm{NO}_{3}$ were purchased from Prolabo, and $\left(2 R^{*}, 3 R^{*}, 4 S^{*}, 5 S^{*}\right)-$ tetrahydrofurantetracarboxylic acid $\left(\mathrm{H}_{4}\right.$ thftc) was from Aldrich. Elemental analyses were performed by MEDAC Ltd. at Chobham, UK and the Service de Microanalyse of the CNRS at Gifsur-Yvette, France.

$\left[C\left(\mathrm{NH}_{2}\right)_{3}\right]_{2}\left[\mathrm{UO}_{2}\left(\mathrm{H}_{2} \mathrm{thftc}\right)_{2}\right]$ (1). $\mathrm{H}_{4}$ thftc $(25 \mathrm{mg}, 0.10 \mathrm{mmol}), \mathrm{UO}_{2}\left(\mathrm{NO}_{3}\right)_{2} \cdot 6 \mathrm{H}_{2} \mathrm{O}(50 \mathrm{mg}$, $0.10 \mathrm{mmol})$ and guanidinium nitrate $(24 \mathrm{mg}, 0.20 \mathrm{mmol})$ were dissolved in demineralized water $(0.6 \mathrm{~mL})$. The solution was left to evaporate slowly at room temperature, giving light yellow 
crystals of complex 1 within ten days $\left(22 \mathrm{mg}, 50 \%\right.$ yield based on $\mathrm{H}_{4}$ thftc). Anal. calcd for $\mathrm{C}_{18} \mathrm{H}_{24} \mathrm{~N}_{6} \mathrm{O}_{20} \mathrm{U}: \mathrm{C}, 24.50 ; \mathrm{H}, 2.74 ; \mathrm{N}, 9.52$. Found: $\mathrm{C}, 24.39 ; \mathrm{H}, 2.71 ; \mathrm{N}, 9.45 \%$.

$\left[\left(\mathrm{UO}_{2}\right)_{3}(\mathrm{Hthftc})_{2}\left(\mathrm{H}_{2} \mathrm{O}\right)_{2}\right] \cdot 2 \mathrm{CH}_{3} \mathrm{CN}(2) . \mathrm{H}_{4}$ thftc $(25 \mathrm{mg}, 0.10 \mathrm{mmol}), \mathrm{UO}_{2}\left(\mathrm{NO}_{3}\right)_{2} \cdot 6 \mathrm{H}_{2} \mathrm{O}(50$ $\mathrm{mg}, 0.10 \mathrm{mmol}), \mathrm{Cd}\left(\mathrm{NO}_{3}\right)_{2} \cdot 4 \mathrm{H}_{2} \mathrm{O}(31 \mathrm{mg}, 0.10 \mathrm{mmol}), 2,2^{\prime}$-bipyridine (16 mg, $\left.0.10 \mathrm{mmol}\right)$, acetonitrile $(0.4 \mathrm{~mL})$, and demineralized water $(0.6 \mathrm{~mL})$ were placed in a $10 \mathrm{~mL}$ tightly closed glass vessel and heated at $140{ }^{\circ} \mathrm{C}$ under autogenous pressure, giving light yellow crystals of complex 2 overnight (11 mg, 23\% yield based on $\mathrm{U}$ ). Anal. calcd for $\mathrm{C}_{20} \mathrm{H}_{20} \mathrm{~N}_{2} \mathrm{O}_{26} \mathrm{U}_{3}$ : C, 16.94; $\mathrm{H}$, 1.42; N, 1.97. Found: C, $17.31 ; H, 1.45 ; \mathrm{N}, 1.92 \%$.

$\left[\left(\mathrm{UO}_{2}\right)_{3} \mathrm{Ag}_{2}(\text { thftc })_{2}\left(\mathrm{H}_{2} \mathrm{O}\right)_{2}\right] \cdot 2 \mathrm{H}_{2} \mathrm{O}(3) . \mathrm{H}_{4}$ thftc $(25 \mathrm{mg}, 0.10 \mathrm{mmol}), \mathrm{UO}_{2}\left(\mathrm{NO}_{3}\right)_{2} \cdot 6 \mathrm{H}_{2} \mathrm{O}(50$ $\mathrm{mg}, 0.10 \mathrm{mmol}), \mathrm{AgNO}_{3}(34 \mathrm{mg}, 0.20 \mathrm{mmol})$, and demineralized water $(1.0 \mathrm{~mL})$ were placed in a $10 \mathrm{~mL}$ tightly closed glass vessel and heated at $140{ }^{\circ} \mathrm{C}$ under autogenous pressure, giving light yellow crystals of complex 3 within two weeks (6 mg, 11\% yield based on U). Anal. calcd for $\mathrm{C}_{16} \mathrm{H}_{16} \mathrm{Ag}_{2} \mathrm{O}_{28} \mathrm{U}_{3}: \mathrm{C}, 12.12 ; \mathrm{H}, 1.02$. Found: $\mathrm{C}, 12.44 ; \mathrm{H}, 1.48 \%$.

$\left[\mathrm{UO}_{2} \mathrm{~Pb}(\right.$ thftc $\left.)\left(\mathrm{H}_{2} \mathrm{O}\right)\right]$ (4). $\mathrm{H}_{4}$ thftc $(25 \mathrm{mg}, 0.10 \mathrm{mmol}), \mathrm{UO}_{2}\left(\mathrm{NO}_{3}\right)_{2} \cdot 6 \mathrm{H}_{2} \mathrm{O}(50 \mathrm{mg}, 0.10$ mmol), $\mathrm{Pb}\left(\mathrm{NO}_{3}\right)_{2}(33 \mathrm{mg}, 0.10 \mathrm{mmol}), \mathrm{AgNO}_{3}(17 \mathrm{mg}, 0.10 \mathrm{mmol})$, and demineralized water (1.0 $\mathrm{mL}$ ) were placed in a $10 \mathrm{~mL}$ tightly closed glass vessel and heated at $140{ }^{\circ} \mathrm{C}$ under autogenous pressure, giving light yellow crystals of complex 4 within two days (13 mg, 18\% yield). Anal. calcd for $\mathrm{C}_{8} \mathrm{H}_{6} \mathrm{O}_{12} \mathrm{PbU}: \mathrm{C}, 13.00 ; \mathrm{H}, 0.82$. Found: $\mathrm{C}, 12.87 ; \mathrm{H}, 1.07 \%$.

$\left[\mathrm{UO}_{2} \mathrm{~Pb}(\right.$ thftc $\left.)\left(\mathrm{H}_{2} \mathrm{O}\right)_{2}\right] \cdot \mathrm{H}_{2} \mathrm{O}(5) . \mathrm{H}_{4}$ thftc $(25 \mathrm{mg}, 0.10 \mathrm{mmol}), \mathrm{UO}_{2}\left(\mathrm{NO}_{3}\right)_{2} \cdot 6 \mathrm{H}_{2} \mathrm{O}(50 \mathrm{mg}$, $0.10 \mathrm{mmol}), \mathrm{Pb}\left(\mathrm{NO}_{3}\right)_{2}(33 \mathrm{mg}, 0.10 \mathrm{mmol})$, and demineralized water $(1.0 \mathrm{~mL})$ were placed in a 10 $\mathrm{mL}$ tightly closed glass vessel and heated at $140{ }^{\circ} \mathrm{C}$ under autogenous pressure, giving light yellow crystals of complex 5 overnight (12 mg, $15 \%$ yield). Anal. calcd for $\mathrm{C}_{8} \mathrm{H}_{10} \mathrm{O}_{14} \mathrm{PbU}$ : C, 12.39; $\mathrm{H}$, 1.30. Found: C, 12.97; H, $1.15 \%$. 
[Ag $3\left(\right.$ Hthftc)] (6). $\mathrm{H}_{4}$ thftc $(25 \mathrm{mg}, 0.10 \mathrm{mmol}), \mathrm{AgNO}_{3}(34 \mathrm{mg}, 0.20 \mathrm{mmol})$, acetonitrile $(0.2 \mathrm{~mL})$, and demineralized water $(0.8 \mathrm{~mL})$ were placed in a $10 \mathrm{~mL}$ tightly closed glass vessel and heated at $140{ }^{\circ} \mathrm{C}$ under autogenous pressure, giving colourless crystals of complex 6 within two weeks (6 mg, $16 \%$ yield based on $\mathrm{Ag}$ ). Anal. calcd for $\mathrm{C}_{8} \mathrm{H}_{5} \mathrm{Ag}_{3} \mathrm{O}_{9}$ : C, 16.90; H, 0.89. Found: $\mathrm{C}$, 17.23; H, 0.99\%.

[Ph 2 thftc) $\left.\left(\mathrm{H}_{2} \mathrm{O}\right)\right]$ (7). $\mathrm{H}_{4}$ thftc $(13 \mathrm{mg}, 0.05 \mathrm{mmol}), \mathrm{Pb}\left(\mathrm{NO}_{3}\right)_{2}(33 \mathrm{mg}, 0.10 \mathrm{mmol})$, acetonitrile $(0.3 \mathrm{~mL})$, and demineralized water $(0.6 \mathrm{~mL})$ were placed in a $10 \mathrm{~mL}$ tightly closed glass vessel and heated at $140{ }^{\circ} \mathrm{C}$ under autogenous pressure, giving colourless crystals of complex 7 overnight (13 mg, 38\% yield). Anal. calcd for $\mathrm{C}_{8} \mathrm{H}_{6} \mathrm{O}_{10} \mathrm{~Pb}_{2}: \mathrm{C}, 14.20 ; \mathrm{H}, 0.89$. Found: $\mathrm{C}, 14.13$; $\mathrm{H}, 0.94 \%$.

Crystallography. The data were collected at $150(2) \mathrm{K}$ on a Nonius Kappa-CCD area detector diffractometer ${ }^{41}$ using graphite-monochromated Mo $\mathrm{K} \alpha$ radiation $(\lambda=0.71073 \AA)$. The crystals were introduced into glass capillaries with a protective coating of Paratone-N oil (Hampton Research). The unit cell parameters were determined from ten frames, then refined on all data. The data (combinations of $\varphi$ - and $\omega$-scans with a minimum redundancy of 4 for $90 \%$ of the reflections) were processed with HKL2000. ${ }^{42}$ Absorption effects were corrected empirically with the program SCALEPACK ${ }^{42}$ The structures were solved by intrinsic phasing with SHELXT, ${ }^{43}$ expanded by subsequent difference Fourier synthesis and refined by full-matrix least-squares on $F^{2}$ with SHELXL-2014. ${ }^{44}$ All non-hydrogen atoms were refined with anisotropic displacement parameters. The hydrogen atoms bound to oxygen and nitrogen atoms were retrieved from difference Fourier maps, and the carbon-bound hydrogen atoms were introduced at calculated positions; all hydrogen atoms were treated as riding atoms with an isotropic displacement parameter equal to 1.2 times that of the parent atom. In the case of complex 6, 3-component twinning was detected with 
PLATON/TwinRotMat ${ }^{45}$ and taken into account; atom $\mathrm{Ag} 3$ is further disordered over two positions (one of them located on an inversion centre), which have been refined with occupancy parameters constrained to sum to unity.

Crystal data and structure refinement parameters are given in Table 1. The molecular plots were drawn with ORTEP- $3^{46}$ and the polyhedral representations with VESTA. ${ }^{47}$ The topological analyses were conducted with TOPOS. ${ }^{48}$

Luminescence Measurements. Emission spectra were recorded on solid samples using a Horiba-Jobin-Yvon Fluorolog spectrofluorometer. The powdered complex was pressed between two silica plates which were mounted such that the faces were oriented vertically and at $45^{\circ}$ to the incident excitation radiation. An excitation wavelength of $420 \mathrm{~nm}$ was used in all cases and the emissions monitored between 450 and $650 \mathrm{~nm}$.

\section{RESULTS AND DISCUSSION}

Synthesis. Complex 1 only was synthesized at room temperature, while the other complexes were obtained under purely hydrothermal (3-5) or solvo-hydrothermal $(\mathbf{2}, \mathbf{6}$ and 7$)$ conditions, the latter with acetonitrile as a co-solvent, in which cases the crystalline materials deposited during the heating phase $\left(140^{\circ} \mathrm{C}\right)$. All the uranyl complexes with variously deprotonated $\mathrm{H}_{4}$ thftc ligands crystallized at room temperature, either in pure water or in organic solvents, in the present and previous studies ${ }^{17}$ are molecular species, whereas all those synthesized by (solvo)hydrothermal methods are coordination polymers (even in the absence of additional metal cations in the final compound, as in the case of complex 2), thus providing a nice illustration of the specific interest of the latter methods for constructing polymeric species. 
An interesting feature of the series is the variable degree of deprotonation, the lower corresponding to the room temperature synthesis, in which two carboxylic protons are retained, while one proton is found in complexes $\mathbf{2}$ and $\mathbf{6}$, full deprotonation being reached in the other cases (full deprotonation was also achieved in the metallamacrocyclic structures, obtained at room temperature in the presence of organic bases ${ }^{17}$ ). It is notable that the protons retained are located on the carboxylic groups at positions 3 and 4 (see below). The reported $\mathrm{p} K_{\mathrm{a} i}(i=1-4)$ values determined by titration for $\mathrm{H}_{4}$ thftc are $0.95,3.40,5.55$ and $6.42,{ }^{49}$ or in the ranges $1.57-2.08,2.86-$ $3.68,4.08-5.40$ and 5.61-7.26,,$^{14,19}$ depending largely on the ionic strength. The low value of $\mathrm{p} K_{\mathrm{a} 1}$ indicates that the electron-withdrawing inductive effects associated with carboxylic and ether groups strongly favour the departure of the first proton. While the most acidic proton is most probably one of either of the two carboxylic groups in the $\alpha$ position with respect to the ether, ${ }^{1}$ there is some uncertainty as to the subsequent deprotonation order, with either the protons at positions 2 and 5 being the more acidic, ${ }^{1}$ or a $2,4,5,3$ deprotonation sequence. ${ }^{14}$ However, esterification of $\mathrm{H}_{4}$ thftc in methanol gave the 2,5-diester, thus showing that the carboxylic groups at those positions are possibly the most acidic. ${ }^{50}$ This does not necessarily mean that these sites must be the ones where a metal ion would most readily replace the proton and it should be noted that coordination to the tetrahydrofuran-O may be an important factor favouring binding to the two adjacent carboxylate units.

Crystal Structures. The complex $\left[\mathrm{C}\left(\mathrm{NH}_{2}\right)_{3}\right]_{2}\left[\mathrm{UO}_{2}\left(\mathrm{H}_{2} \text { thftc }\right)_{2}\right](\mathbf{1})$, represented in Figure 1, contains a mononuclear dianionic species in which the unique hexagonal bipyramidal uranium atom, located on an inversion centre, is bound to the tridentate, oxydiacetate-like site of two ligands, both carboxylic groups at the 3 and 4 positions retaining their proton. Formation of two five-membered chelate rings within the tridentate unit must be favoured over that of one seven- 
membered ring that would result from chelation by the groups in the 3 and 4 positions. ${ }^{15}$ The U$\mathrm{O}($ carboxylate) $[2.399(3)$ and $2.447(3) \AA]$ and $\mathrm{U}-\mathrm{O}($ ether) $[2.640(3) \AA]$ bond lengths are unexceptional, and they are larger by $\sim 0.09 \AA$ than those in the metallamacrocycles previously reported $^{17}$ as a consequence of the different coordination number, seven in the latter complexes and eight in $\mathbf{1}$; in particular, these bond lengths are very close to those measured in eight-coordinate uranyl complexes with oxydiacetate $\left(2.36-2.46 \AA\right.$ and $2.62-2.72 \AA$, respectively). ${ }^{51-54}$ The six equatorial donors define a regularly puckered plane with a root mean square (rms) deviation of $0.27 \AA$. The $\mathrm{H}_{2} \mathrm{thftc}^{2-}$ anion is, as expected given the mild preparative conditions, in the achiral trans,cis,trans $\left(2 R^{*}, 3 R^{*}, 4 S^{*}, 5 S^{*}\right)$ form and the complex crystallizes in a centrosymmetric space group. The ligand adopts an envelope conformation with the carbon atom $\mathrm{C} 1$, next to $\mathrm{O} 10$, being displaced by $0.555(6) \AA$ from the average plane defined by the four other atoms of the ring (rms deviation $0.015 \AA$ ). This is at variance with the conformation possessing mirror symmetry found in the cyclic polynuclear species, in which the ether group is out of the plane defined by the four carbon atoms. ${ }^{17}$ Due to the presence of carboxylic groups and proton-rich $\mathrm{C}\left(\mathrm{NH}_{2}\right)_{3}{ }^{+}$guanidinium counterions, extensive hydrogen bonding interactions are present. The carboxylic groups are hydrogen bonded to the uncoordinated oxygen atoms of the carboxylate groups from neighbouring

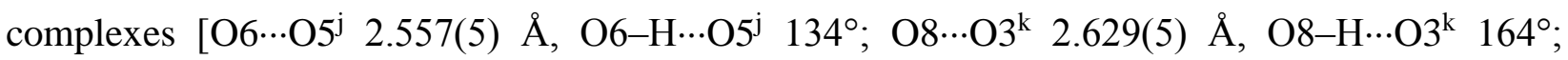
symmetry codes: $\mathrm{j}=1-x, 2-y, 1-z$ and $\mathrm{k}=1-x, 1-y, 2-z]$, which gives rise to the formation of sheets parallel to $(1-1-1)$ with alternating cations and anions arranged into staggered rows, as shown in Figure 1. The guanidinium counterion is involved in five intra-sheet hydrogen bonds, all with carboxylate oxygen atoms, with one of the protons involved in a bifurcated bond, while two protons bound to different nitrogen atoms are hydrogen bonded to the same oxygen atom. The other two hydrogen bonds formed by the counterion involve carboxylic oxygen atoms (O7 and O9) 
from an adjacent sheet, so that a 3D network is formed. Overall, the hydrogen bonds with guanidinium are significantly longer than those involving carboxylic donors [N‥O 2.877(6)3.204(6) $\AA, \mathrm{N}-\mathrm{H} \cdots \mathrm{O} 132-162^{\circ}$ ]. A weak inter-sheet interaction between a carbon-bound proton of the ligand and the oxo atom $\mathrm{O} 1$, with a $\mathrm{H} \cdots \mathrm{O}$ distance of $2.27 \AA$, may also be present. With a Kitaigorodski packing index (KPI, estimated with PLATON ${ }^{45}$ ) of 0.73 , the packing displays no free space.

Although it was synthesized in the presence of cadmium(II) nitrate and 2,2'-bipyridine, complex 2, $\left[\left(\mathrm{UO}_{2}\right)_{3}(\mathrm{Hthftc})_{2}\left(\mathrm{H}_{2} \mathrm{O}\right)_{2}\right] \cdot 2 \mathrm{CH}_{3} \mathrm{CN}$, does not contain these additional species and is a unique case of a polymeric homometallic uranyl complex obtained from $\mathrm{H}_{4}$ thftc. The additional species in the reaction mixture could influence the solution equilibria both through nitrate and $2,2^{\prime}-$ bipyridine complexation of uranyl and $\mathrm{pH}$ effects, though the acidity of the aqua-Cd(II) cation would presumably counter the basicity of 2,2'-bipyridine and it can only be said that the overall consequence is to enhance the degree of deprotonation of $\mathrm{H}_{4}$ thftc. Note that in only three of the present seven cases does the stoichiometry of the isolated solid reflect that of the reaction mixture. The asymmetric unit of $\mathbf{2}$ includes two independent uranium atoms, one of them (U1) located on an inversion centre, and one $\mathrm{Hthftc}^{3-}$ anion (Figure 2). Atom U1 is in the same environment as its counterpart in complex 1, with similar U-O(carboxylate) [2.386(3) and 2.447(4) $\AA]$ and UO(ether) $[2.660(3) \AA]$ bond lengths. Atom U2 is chelated by two carboxylic groups in the positions 2 and 3 (atoms $\mathrm{O} 7$ and $\mathrm{O} 8$ ) to give a 7-membered ring, and it is also bound to two more carboxylate oxygen atoms from two different ligands and a water molecule, its environment being thus pentagonal bipyramidal with unexceptional U-O(carboxylate) bond lengths [2.321(4)-2.432(4) $\AA]$. The ligand retains the trans, cis, trans $\left(2 R^{*}, 3 R^{*}, 4 S^{*}, 5 S^{*}\right)$ form, with an envelope conformation, the carbon atom $\mathrm{C} 2$, next to $\mathrm{O} 12$, being at $0.613(8) \AA$ from the average plane defined by the other 
four atoms of the ring (rms deviation $0.013 \AA$ ). Each ligand is bound to four metal atoms, its three carboxylate groups being bridging bidentate $\left(\mu_{2}-\eta^{1}: \eta^{1}\right.$ coordination mode $)$ and the carboxylic acid group being uncoordinated (Scheme 1). Only U2 and $\mathrm{Hthftc}^{3-}$ are nodes (three- and four-fold, respectively) in the $2 \mathrm{D}$ polymeric assembly parallel to $\left(\begin{array}{lll}1 & 1 & 0\end{array}\right)$, with the point (Schläfli) symbol $\left\{4^{2} .6^{3} .8\right\}\left\{4^{2} .6\right\}$ (topological type $\mathrm{V}_{2} \mathrm{O}_{5}$ ). As shown in Figure 2, this arrangement can be viewed as formed of an alternation of rows of differently sized parallelograms and it is different from the $\left\{4^{4} \cdot 6^{2}\right\}$ network found in the uranyl/copper(II) heterometallic complex of thftc ${ }^{4-}$, in which the copper cations have no topological role. ${ }^{18}$ The carboxylic proton is hydrogen bonded to the

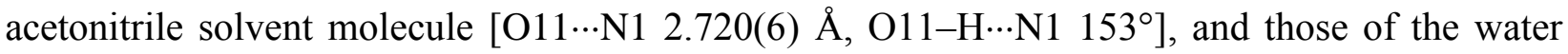
molecule are bonded to either a carboxylate or a carboxylic oxygen atom pertaining to the same or

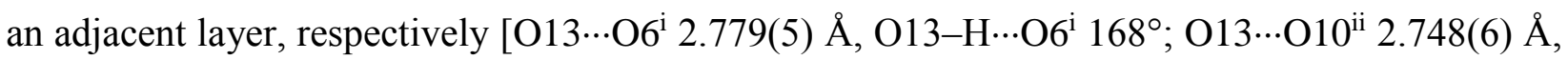
O13-H $\cdots \mathrm{O} 10^{\mathrm{ii}} 146^{\circ}$; symmetry codes: $\mathrm{i}=1-x, 2-y, 2-z$ and $\left.\mathrm{ii}=1-x, 1-y, 2-z\right]$. The oxo atoms $\mathrm{O} 2$ and $\mathrm{O} 3$ may be involved in weak interactions with carbon-bound hydrogen atoms from a ligand of the neighbouring sheet $(\mathrm{H} \cdots \mathrm{O} 2.45 \AA)$ and the acetonitrile molecule (2.69-2.79 $\AA$ ). The KPI of 0.71 indicates a compact arrangement devoid of free spaces.

The asymmetric unit in the heterometallic complex $\left[\left(\mathrm{UO}_{2}\right)_{3} \mathrm{Ag}_{2}(\operatorname{thftc})_{2}\left(\mathrm{H}_{2} \mathrm{O}\right)_{2}\right] \cdot 2 \mathrm{H}_{2} \mathrm{O}(3)$ contains two uranium atoms, one of them (U2) located on an inversion centre, one silver(I) cation and one fully deprotonated thftc ${ }^{4-}$ ligand (Figure 3). Like U1 in complexes $\mathbf{1}$ and $\mathbf{2}$, atom U2 is bound to the tridentate site of two ligands, with unexceptional $\mathrm{U}-\mathrm{O}$ (carboxylate) [2.373(4) and 2.407(5) $\AA$ ] bond lengths and a U-O(ether) bond length of 2.746(5) Å slightly longer than usual. Atom U1 is chelated by two carboxylate groups in the 2 and 3 positions of one ligand and it is bound to two more carboxylate donors from two more ligands [U-O(carboxylate) bond lengths 2.315(2)-2.453(4) $\AA$ ] and to a water molecule, as for U2 in complex 2 . A centrosymmetric pair of 
silver atoms connected through a strong argentophilic interaction [2.7773(13) $\AA]$ is trapped between two $\mu_{2}-\eta^{1}: \eta^{1}$ carboxylate groups, which is a usual motif, with more than 60 comparable examples reported in the Cambridge Structural Database (CSD, Version 5.37), ${ }^{55,56}$ giving an average $\mathrm{Ag} \cdots \mathrm{Ag}$ distance of 2.89(10) $\AA$. The $\mathrm{Ag}-\mathrm{O}$ (carboxylate) bond lengths of 2.169(5) and 2.186(5) $\AA$ are unexceptional [average 2.25(9) $\AA$ from the CSD]. Ag1 is involved in three longer contacts, one with the carboxylate atom $\mathrm{O}^{1}[2.706(5) \AA ;$ symmetry code: $1=x-1, y, z]$ and the others with the uranyl oxo atoms $\mathrm{O} 3^{1}[2.899(5) \AA]$ and $\mathrm{O} 1^{11}[2.974(5) \AA$; symmetry code: $11=x, y$ $+1, z]$. The $\mathrm{Ag}-\mathrm{O}$ bond lengths reported in the CSD range approximately from 2.0 to $3.1 \AA$ [average 2.45(16) $\AA$ ], so that the latter interactions with the oxo groups may be considered as weak interactions at best, as confirmed by the absence of significant lengthening of the $\mathrm{U}=\mathrm{O}$ bond lengths $[1.760(5)-1.776(5) \AA]$; only the bond with $\mathrm{O}^{1}$ is shown in Figure 3. Much stronger $\mathrm{Ag}-\mathrm{O}$ (uranyl) bonds, with distances as short as $2.38-2.58 \AA$, have been reported. ${ }^{57-59}$ Here again, the ligand is in the trans, cis, trans $\left(2 R^{*}, 3 R^{*}, 4 S^{*}, 5 S^{*}\right)$ form, and the envelope conformation brings atom $\mathrm{C} 1$, next to 012 , to $0.612(9) \AA$ from the mean plane defined by the other four atoms of the ring (rms deviation $0.006 \AA$ ). The ligand is bound to four uranyl ions, in a similar way as that found in complex 2, the difference arising from replacement of the uncomplexed carboxylic group by a silver-bound carboxylate (Scheme 1). Considering only uranyl cations, a 2D assembly analogous to that in 2 is thus formed, with the $\mathrm{V}_{2} \mathrm{O}_{5}$ topological type and parallel to (1 -1 1). Instead of being hydrogen bonded to one another, the layers are united into a 3D coordination polymer by the bridging $\mathrm{Ag}_{2}$ moieties. The coordinated and lattice water molecules are hydrogen bonded to oxo and carboxylato groups, and to one another. The KPI of 0.73 ( 0.68 with solvent excluded) indicates that no spaces or channels of significant size are present. 
Two crystalline complexes combining uranyl and lead(II) cations have been obtained, $\left[\mathrm{UO}_{2} \mathrm{~Pb}\right.$ (thftc) $\left.\left(\mathrm{H}_{2} \mathrm{O}\right)\right](4)$ and $\left[\mathrm{UO}_{2} \mathrm{~Pb}(\right.$ thftc $\left.)\left(\mathrm{H}_{2} \mathrm{O}\right)_{2}\right] \cdot \mathrm{H}_{2} \mathrm{O}(5)$, their syntheses differing by the additional presence of silver nitrate in that of compound $\mathbf{4}$. The asymmetric unit in $\mathbf{4}$ contains one uranyl and one lead(II) cation, and one fully deprotonated thftc ${ }^{4-}$ ligand (Figure 4). The most prominent difference with the previous cases is that the tridentate coordination site is now occupied by lead(II) (as it was by copper(II) in the previously reported heterometallic complex ${ }^{18}$ ), and U(VI) is found exclusively in a pentagonal bipyramidal environment. The uranium atom is chelated by two carboxylate groups from the 2 and 3 positions, as in complexes $\mathbf{2}$ and $\mathbf{3}$, but here this happens twice and involves two ligands; one more carboxylate oxygen atom from a third ligand completes the pentagonal bipyramidal environment [U-O(carboxylate) bond lengths in the range 2.333(9)2.453(9) $\AA]$. The lead(II) cation is bound to the ether atom O11 [2.859(8) $\AA$; the average $\mathrm{Pb}-$ O(ether) bond length from the CSD is $2.75(11) \AA]$, to seven carboxylate oxygen atoms [2.553(9)3.108(9) $\AA]$, among which four pertain to two chelating groups, and to a water molecule [2.439(9) $\AA]$, which gives a nine-coordinate environment of very irregular geometry possibly influenced by the presence of a stereochemically active lone pair. ${ }^{60-62}$ Holodirected bonding should be favoured in the present case, ${ }^{60}$ but it should be noted that all the $\mathrm{Pb}-\mathrm{O}$ (carboxylate) bond lengths are somewhat long and several of them may correspond to rather weak bonds only, a situation commonly encountered in $\mathrm{Pb}^{\mathrm{II}}$ complexes. ${ }^{62} \mathrm{The}_{\mathrm{Thtc}}{ }^{4-}$ ligand is in the same form as in the previous complexes, with atom $\mathrm{C} 2$, next to O11, deviating by $0.56(2) \AA$ from the average plane defined by the four other atoms of the ring (rms deviation $0.010 \AA$ ). The ligand is bound to seven (four lead(II) and three uranyl) metal cations (Scheme 1), and this high connectivity gives rise to the formation of a 3D framework, a situation different from that in the copper(II)-containing complex previously reported, in which the terminal nature of the bipy and water ligands bound to $\mathrm{Cu}^{\mathrm{II}}$ limited the 
polymer propagation. ${ }^{18}$ Planar sheets parallel to $\left(\begin{array}{lll}1 & 1 & 0\end{array}\right)$ are apparent, that are connected to one another through lead-carboxylate bonds, a feature reminiscent of that found in complex 3 . However, the sheets here are heterometallic, with alternating rows of uranyl dimers (with double carboxylate bridges) and lead cations directed along the $c$ axis (Figure 4). The KPI of 0.81 is indicative of a very compact arrangement.

With respect to that in $\mathbf{4}$, the asymmetric unit in $\mathbf{5}$ contains two additional water molecules, one coordinated and one free, but the connectivity is different. The uranium atom is once more chelated by two carboxylate groups in 2 and 3 positions, and is bound to two more carboxylate donors from two different ligands and one water molecule [U-O(carboxylate) bond lengths in the range 2.283(4)-2.417(3) $\AA$ ]. The tridentate coordination site is here again occupied by the lead(II) cation, with a $\mathrm{Pb}-\mathrm{O}$ (ether) bond length $[2.675(4) \AA]$ shorter than that in 4 . The lead(II) cation is bound to six carboxylate oxygen atoms $[2.580(4)-2.759(4) \AA$, with a longer contact at 3.031(5) $\AA$ with the bridging atom O9, part of an unsymmetrical chelating group] and to a water molecule $[2.502(4) \AA]$. It is also possibly bonded to the uranyl oxo atom O1, at 2.999(4) $\AA$, a value significantly lower than that of 3.176(5) $\AA$ found in a complex with $1,3,5$-benzenetriacetate. ${ }^{40}$ Distances for such oxo-cation interactions involving lanthanides are 2.822(4) $\AA$ for Ce(III) and 2.792(6) $\AA$ for $\mathrm{Nd}(\mathrm{III}){ }^{63}$ the ionic radius of $\mathrm{Pb}^{\mathrm{II}}$ being about $0.1 \AA$ larger than that of $\mathrm{Ce}(\mathrm{III})$, the present distance seems compatible with the existence of such an interaction, but the absence of significant $\mathrm{U}=\mathrm{O}$ bond lengthening [U1-O1 1.774(4), U1-O2 1.763(4) $\AA$ ] indicates however that it is not a very strong one. $\mathrm{Pb} 1$ is thus in an irregular nine-coordinate environment that would have a hemidirected character but for the contact with the oxo group. The ligand is in the same form as in the other compounds, but the envelope conformation has atom C4 (in the succinate-like part) displaced by $0.653(8) \AA$ from the mean plane defined by the four other atoms of the ring (rms deviation $0.019 \AA$ ), a conformation previously found, for example, in the cesium or calcium salts 
of partially or fully deprotonated $\mathrm{H}_{4}$ thftc, ${ }^{1}$ or in the heterometallic uranyl/copper(II) complex of the latter. ${ }^{18}$ As in complex 4, the ligand is bound to seven (four lead(II) and three uranyl) metal cations, although they are differently arranged in both compounds (Scheme 1), and this high degree of connectivity results here also in the formation of a 3D framework (KPI 0.78), in which thick layers parallel to $\left(\begin{array}{lll}0 & 0 & 1\end{array}\right)$ can be discerned (Figure 5). The water molecules are hydrogen bonded to one another and to carboxylate and oxo groups.

Since no structure of a homometallic complex formed by $\mathrm{H}_{4}$ thftc with either silver(I) or lead(II) has been reported, it appeared worthwhile to synthesize such compounds so as to compare the coordination modes observed to those in the heterometallic complexes. In the event, this also proved interesting in regard to the selection of isomers of $\mathrm{H}_{4}$ thftc apparently present in the solvothermal reaction mixtures. The asymmetric unit in $\left[\mathrm{Ag}_{3}(\mathrm{Hthftc})\right]$ (6) contains three independent silver cations, one of them (Ag3) being disordered over two positions (one of them located on an inversion centre), and one $\mathrm{Hthftc}^{3-}$ ligand (Figure 6). The tridentate site is occupied by one silver(I) cation (Ag1), but the Ag1-O9 bond length of 2.772(7) $\AA$ indicates that the interaction is not a strong one $[\mathrm{Ag}-\mathrm{O}$ (ether) bond lengths reported in the CSD vary widely in the 2.15-3.16 $\AA$ range, with a maximum around $2.55 \AA$, large values being often associated to constrained ligands, as is the case here]. The Ag-O(carboxylic/ate) bond lengths in 6 are in the range 2.239(7)-2.765(6) $\AA$ [average 2.45(15) $\AA$ ], and the coordination environments are very irregular (even when only the shorter contacts are considered). The most unusual feature of this structure concerns the $\mathrm{Hthftc}^{3-}$ ligand, which is in the chiral cis,trans,trans $\left(2 R^{*}, 3 S^{*}, 4 S^{*}, 5 S^{*}\right)$ form, with the three carboxylate groups located on one side of the ring and the carboxylic group on the other side. As noted previously, inversion of the ring carbon atoms of $\mathrm{H}_{4}$ thftc has been observed in a family of zinc(II) complexes, ${ }^{8}$ and the same phenomenon arises with $1,2,3,4$ cyclobutanetetracarboxylic acid (cis,trans, cis and trans,trans,trans isomers) ${ }^{18,21,23,24}$ and with 
1,2,3,4,5,6-cyclohexanehexacarboxylic acid (all-cis and all-trans isomers). ${ }^{20,22,25}$ The cyclopentane ring is here once more in an envelope conformation, albeit somewhat more distorted than in complexes $\mathbf{1}-\mathbf{5}$, with atom $\mathrm{C} 1$, next to O9, displaced by $0.547(12) \AA$ from the mean plane defined by the four other atoms (rms deviation $0.051 \AA$ ). With about 11 silver(I) cations bound to the ligand (the value may vary due to the disorder affecting Ag3; only one possible arrangement is shown in Scheme 1), it is unsurprising that the polymer generated is 3D and extremely intricate. The cations appear to be concentrated into layers parallel to $\left(\begin{array}{lll}1 & 0 & 0\end{array}\right)$, these layers containing cylindrical channels with a diameter of $\sim 5 \AA$ running along the $c$ axis (Figure 6). Notwithstanding these narrow free spaces, the KPI value of 0.79 (calculated for only one position of Ag3) indicates that this compound cannot be considered as really porous, at least for any practical purpose.

Unlike the homometallic $\mathrm{Ag}^{\mathrm{I}}$ complex but like all other complexes in the present study, the homometallic $\mathrm{Pb}^{\mathrm{II}}$ complex, [ $\mathrm{Pb}_{2}($ thftc $\left.)\left(\mathrm{H}_{2} \mathrm{O}\right)\right](7)$, contains the ligand in its trans, cis, trans $\left(2 R^{*}, 3 R^{*}, 4 S^{*}, 5 S^{*}\right)$ form. There are two inequivalent metal atoms, with $\mathrm{Pb} 1$ bound to the tridentate site of the ligand, and an 8-membered chelate ring formed on $\mathrm{Pb} 2$ through binding of just the carboxylate-O donors on ring positions 2 and $5(\mathrm{O} 1$ and $\mathrm{O} 3)$ and not of their intervening ether-O atom. $\mathrm{Pb} 1$ is also bound to four more carboxylate oxygen atoms (among which $\mathrm{O} 7$ and $\mathrm{O} 8$ pertain to a chelating group), and to two water molecules $[\mathrm{Pb} 1-\mathrm{O}$ (water) bond lengths $2.813(5)$ and 2.962(5) $\AA$ ]. Pb2 has no water ligand, and it is bound to nine carboxylate oxygen donors, all but O2 being involved in chelation through either one or two carboxylate groups. All the chelating interactions are quite unsymmetrical, and both $\mathrm{Pb} 1$ and $\mathrm{Pb} 2$ are 9-coordinate with an irregular geometry, probably best described as holodirected. The Pb1-O9(ether) bond length of 2.729(4) $\AA$ lies between those found in complexes $\mathbf{4}$ and $\mathbf{5}$. The $\mathrm{Pb}-\mathrm{O}$ (carboxylate) bond distances vary considerably [2.451(5)-3.000(5) $\AA$ for Pb1, 2.369(4)-3.089(5) A for Pb2] but over a similar range 
to that found in the heterometallic complexes. The ligand ring conformation is here again of the envelope type and an atom in the succinate-like part (as in complex 5), C3, is at 0.623(9) $\AA$ from the average plane defined by the four other atoms (rms deviation $0.040 \AA$ ). All nine O-donors of the ligand are involved in coordination, through chelating and bridging interactions (with in particular a regular $\mu_{3}-\eta^{1}: \eta^{2}: \eta^{1}$ coordination mode for the two carboxylate groups of the succinatelike part), to nine $\mathrm{Pb}^{\mathrm{II}}$ centres (Scheme 1). The water molecule is hydrogen bonded to carboxylate oxygen atoms $\left[\mathrm{O} \cdots \mathrm{O}\right.$ distances $2.903(6)$ and $2.738(6) \AA$, $\mathrm{O}-\mathrm{H} \cdots \mathrm{O}$ angles 151 and $\left.168^{\circ}\right]$. The complex is a 3D coordination polymer in which layers of ligand molecules parallel to $\left(\begin{array}{lll}0 & 1 & 0\end{array}\right)$ can be considered to be linked within and bridged by layers containing both $\mathrm{Pb} 1$ and $\mathrm{Pb} 2$. The high KPI value of 0.86 is indicative of a dense arrangement.

Luminescence properties. Solid state emission spectra have been recorded under excitation at a wavelength of $420 \mathrm{~nm}$, a value suitable for excitation of uranyl, ${ }^{64}$ for compounds $\mathbf{1}-$ 7, and those for the uranium-containing complexes 1-5 are shown in Figure 8. The spectra of the uranyl-only complexes $\mathbf{1}$ and $\mathbf{2}$, and that of the uranyl/lead(II) complex $\mathbf{4}$ show intense and wellresolved uranyl emission displaying the vibronic progression corresponding to the $S_{11} \rightarrow S_{00}$ and $S_{10} \rightarrow S_{0 v}(v=0-4)$ states. $^{65}$ The maxima are at 496, 518, 542, 568 and $596 \mathrm{~nm}$ for complex $\mathbf{1}$, while they are blue-shifted by $2 \mathrm{~nm}$ in $\mathbf{2}$, and red-shifted by $2 \mathrm{~nm}$ in 4; some changes in the relative intensities of the peaks are also observed, which could be due at least partly to a very broad single peak seemingly convoluted with the uranyl spectrum in the case of 1 and $\mathbf{4}$. Weak bands at $\sim 477$ and $\sim 482 \mathrm{~nm}$ in the spectra of 2 and 4 , respectively, correspond to a shoulder of the first intense band in the spectrum of $\mathbf{1}$. The positions of the main maxima are very close to those recently measured in an 8-coordinate uranium(VI) complex with 2,5-thiophenedicarboxylate ligands and 
$\operatorname{Ag}(\text { bipy })_{2}{ }^{+}$counterions, ${ }^{66}$ and also to those in several 7 -coordinate complexes, with $4,4^{\prime}-$ $\left(1,1,1,3,3,3\right.$-hexafluoroisopropylidene)diphthalate, ${ }^{67} \quad 1,1^{\prime}$-biphenyl-2,2',6,6'-tetracarboxylate, ${ }^{68}$ terephthalate, ${ }^{69,70}$ and 2,5-thiophenedicarboxylate, ${ }^{70}$ irrespective of the different uranium coordination numbers present here ( 8 in $\mathbf{1 ,} 7$ in $\mathbf{4}$ and a mixture of both in 2 ), and they are all redshifted, by $\sim 10-20 \mathrm{~nm}$, with respect to the values, measured under identical experimental conditions, generally reported for 8 -coordinate uranium(VI) carboxylate complexes. ${ }^{25,40,70-76}$ Spectra that are nearly identical for 7 - and 8 -coordinate complexes have also been reported in 4,4'biphenyldicarboxylate complexes, with maxima positions blue-shifted by $\sim 6 \mathrm{~nm}$ with respect to those for $1 .^{77}$ The slightly unsymmetrical shape of the main peaks for complex 2 may be due to the convolution of signals corresponding to these two coordination numbers. Clearly, if the coordination number is a known factor governing the uranyl emission spectra, other factors such as the ligand strength are also at play. ${ }^{78,79}$ The spectra of the silver- and lead-containing heterometallic complexes $\mathbf{3}$ and $\mathbf{5}$ show strong quenching of uranyl luminescence, attributed to the additional metal cations providing nonradiative relaxation pathways. ${ }^{80}$ Such quenching is not general with silver(I) ${ }^{66,81,82}$ although it has been previously observed to occur. ${ }^{40,80}$ In the spectrum of complex $\mathbf{3}$, in which 7- and 8-coordination of uranium coexist, only three very weak peaks at $\sim 481,502$ and $521 \mathrm{~nm}$ are apparent, these values being identical to those measured for several 8coordinate uranyl complexes with carboxylates..$^{25,40,70-76}$ These three peaks are superimposed upon a broad emission centred near $490 \mathrm{~nm}$; given that the homometallic $\mathrm{Ag}^{\mathrm{I}}$ complex 6 displays a broad, weak emission centred near $550 \mathrm{~nm}$ (Figure S1, Supporting Information), it is assumed that the emission at $490 \mathrm{~nm}$ in complex $\mathbf{3}$ is due to the Ag-carboxylate entity. In a previous study with 1,3,5-benzenetriacetate, lead(II) evinced no major quenching effect, ${ }^{40}$ as shown here also by complex $\mathbf{4}$, but in contrast to what is observed for complex $\mathbf{5}$. The emission in the latter complex 
is again extremely weak, with maxima at $483,499,521,545$ and $572 \mathrm{~nm}$, very close to those for complex 4 (it is notable that the lead(II) complex 7 is non-emissive, see Supporting Information). The origin of the emission intensity difference between $\mathbf{4}$ and $\mathbf{5}$ may be subtle, since the coordination environment of uranium(VI) is very similar in the two cases, although somewhat more irregular in complex $\mathbf{5}$, but the bound water molecule in the latter offers an obvious pathway for non-radiative energy loss from uranium(VI) which is not available in complex 4 (although one coordinated water is also present in the strongly emitting complex 2). Assuming that energy loss from excited uranium(VI) could occur by transfer to a nearby metal ion, it is of interest that in the two structures each lead(II) cation is within $5 \AA$ of two uranium(VI), and each uranium(VI) within $5 \AA$ of two lead(II) centres, thus comprising PbUPbU parallelograms with sides of 4.6335(7) and 4.9402(8) $\AA$ in complex 4 and 4.6837(5) and 4.7089(5) $\AA$ in complex 5, the difference in the minimum separation being clearly rather slight. The average vibronic splitting energies for the $S_{10}$ $\rightarrow S_{0 v}$ transitions are in the range of $852-859 \mathrm{~cm}^{-1}$ for complexes $\mathbf{1 , 2 , 4}$ and $\mathbf{5}$, these values being comparable to that of $852 \mathrm{~cm}^{-1}$ measured in uranyl malonates, ${ }^{65}$ as well as to those in uranyl complexes with other polycarboxylates..$^{66,70,75}$

\section{CONCLUSIONS}

The present work provides further illustration of the fact that the solid-state coordination chemistry of uranyl ion can be radically modified by the presence of other metal ions. Silver(I) and lead(II) provide important examples of this effect in that the origins of their influence appear to be

quite different. Thus, $\mathrm{Pb}^{\mathrm{II}}$, like $\mathrm{Cu}^{\mathrm{II}}$, prevents uranyl ion adopting certain coordination modes, in particular, tridentate coordination involving the ether-O, by preferentially binding in the same manner. Silver(I), in contrast, has a coordination chemistry which is quite different to that of uranyl 
ion $\left(\right.$ and $\mathrm{Pb}^{\mathrm{II}}$ ) and while this does not prevent uranyl ion adopting tridentate coordination of thftc ${ }^{4-}$ anions and thus may be a reason why the ligand is found still in its trans,cis,trans $\left(2 R^{*}, 3 R^{*}, 4 S^{*}, 5 S^{*}\right)$ form, binding of $\mathrm{Ag}_{2}$ dimers to the ligand creates an "exotic" unit within the lattice which modifies the way the uranyl entities are connected. The effects of $\mathrm{Ag}^{\mathrm{I}}$ and $\mathrm{Pb}^{\mathrm{II}}$ in uranyl-organic coordination polymers are however much dependent on the nature of the ligand, as indicated by recent findings that, in a series of complexes with $1,3,5$-benzenetriacetate, $\mathrm{Pb}^{\mathrm{II}}$ generates less marked changes in the uranyl coordination mode than $\mathrm{Ag}^{\mathrm{I}},{ }^{40}$ an outcome at variance with that observed here and which seems related to the peculiar nature of the tridentate coordination site of thftc ${ }^{4-}$, for the occupation of which uranyl and $\mathrm{Pb}^{\mathrm{II}}$ are in competition.

The specific coordination preferences of silver(I) may also explain its deposition as the complex of the $\left(2 R^{*}, 3 S^{*}, 4 S^{*}, 5 S^{*}\right)$ isomer of the ligand when no other metal ion is present. That this is the only isomer so far found in the two cases where isomerization of the starting species can be confirmed may mean that the "library" of equilibrated isomers consists of only two members $\left(R^{*}, R^{*}, S^{*}, S^{*}\right.$ and $\left.R^{*}, S^{*}, S^{*}, S^{*}\right)$, or that an unfavourable equilibrium is displaced by precipitation, or that the isolated complexes are simply the least soluble materials (when crystallised at room temperature). Further work is required to characterize the equilibrium achieved under hydrothermal conditions with the acid alone and an interesting further experiment would be to search for a metal precipitating the $\left(2 R^{*}, 3 S^{*}, 4 S^{*}, 5 S^{*}\right)$ isomer as a racemic mixture ("spontaneous resolution") rather than as a racemic compound.

From a crystal engineering viewpoint, it is notable that the homometallic uranyl complexes obtained up to now are either discrete, molecular species when synthesized at room temperature, as complex $\mathbf{1}$ in the present study or the metallamacrocycles previously reported, ${ }^{17}$ or a $2 \mathrm{D}$ coordination polymer when isolated from a solvo-hydrothermally treated solution (complex 2). In contrast to the 2D network observed in the uranyl/copper(II) complex 
$\left[\mathrm{UO}_{2} \mathrm{Cu}\left(\right.\right.$ thftc) $($ bipy $\left.)\left(\mathrm{H}_{2} \mathrm{O}\right)\right] \cdot 2 \mathrm{H}_{2} \mathrm{O},{ }^{18}$ in which the terminal bipy ligand plays a role in restricting the dimensionality, all the heterometallic complexes reported here, with silver(I) and lead(II) additional cations, crystallize as 3D frameworks as a result of the high connectivity of the ligand which is bound to seven metal atoms in all cases, and the bridging nature of all cations (the high coordination number of lead(II) cations in particular being conducive to the formation of intricate arrangements). 3D frameworks are also found in the homometallic silver(I) and lead(II) complexes, and the ligand connectivity achieved in these cases is even higher, with $9(\mathrm{Cu})$ or $11(\mathrm{Ag})$ cations bound to the ligand. The $\mathrm{UO}_{2} / \mathrm{Pb} / \mathrm{Ag} / \mathrm{H}_{4}$ thftc system has obviously a rich potential for the building of 3D assemblies, none of those described here presenting significant porosity however. Intense and well resolved solid state emission in the 470-600 nm range showing the vibronic fine structure typical of the uranyl cation is displayed by the homometallic complexes $\mathbf{1}$ and $\mathbf{2}$, and the uranyl/lead(II) heterometallic complex 4 , while uranyl emission in the silver(I)- and lead(II)containing complexes $\mathbf{3}$ and $\mathbf{5}$ is largely quenched.

\section{ASSOCIATED CONTENT}

\section{Accession Codes}

CCDC 1500859-1500865 contains the supplementary crystallographic data for this paper. These data can be obtained free of charge via www.ccdc.cam.ac.uk/data_request/cif, or by emailing data_request@ccdc.cam.ac.uk, or by contacting The Cambridge Crystallographic Data Centre, 12, Union Road, Cambridge CB2 1EZ, UK; fax: +44 1223336033.

\section{Supporting Information}

The Supporting Information is available free of charge on the ACS Publications website at DOI:. Emission spectra of complexes 6 and 7. (PDF) 


\section{AUTHOR INFORMATION}

\section{Corresponding Authors}

*E-mail: pierre.thuery@cea.fr (P. T.)

*E-mail: harrowfield@unistra.fr (J. H.)

\section{Notes}

The authors declare no competing financial interest. 


\section{REFERENCES}

1. Barnes, J. C.; Paton, J. D. Acta Crystallogr., Sect. C 1984, 40, 1809-1812.

2. Barnes, J. C. Acta Crystallogr., Sect. E 2002, 58, m378-m380.

3. Guillem, M. C.; Latorre, J.; Martínez-Máñez, R.; Payá, J.; García-Granda, S.; Pérez-Carreño, E.; Gómez-Beltrán, F. Polyhedron 1993, 12, 1681-1687.

4. Hanson, K.; Calin, N.; Bugaris, D.; Scancella, M.; Sevov, S. C. J. Am. Chem. Soc. 2004, 126, $10502-10503$.

5. Wang, X. Y.; Sevov, S. C. Chem. Mater. 2007, 19, 3763-3766.

6. Wang, X. Y.; Scancella, M.; Sevov, S. C. Chem. Mater. 2007, 19, 4506-4513.

7. Ai, W.; He, H.; Liu, L.; Liu, Q.; Lv, X.; Li, J.; Sun, D. CrystEngComm 2008, 10, 1480-1486.

8. Zhang, L.; Zhang, J.; Li, Z. J.; Qin, Y. Y.; Lin, Q. P.; Yao, Y. G. Chem. - Eur. J. 2009, 15, 9891000.

9. Zhang, L.; Lin, Q. P.; Li, Z. J.; Zhang, J.; Qin, Y. Y.; Cheng, J. K.; Yao, Y. G. CrystEngComm 2009, 11, 1201-1203.

10. Zhang, L.; Li, Z. J.; Lin, Q. P.; Zhang, J.; Yin, P. X.; Qin, Y. Y.; Cheng, J. K.; Yao, Y. G. CrystEngComm 2009, 11, 1934-1939.

11. Liu, C. S.; Sañudo, E. C.; Hu, M.; Zhou, L. M.; Guo, L. Q.; Ma, S. T.; Gao, L. J.; Fang, S. M. CrystEngComm 2010, 12, 853-865.

12. Zheng, Y. Q.; Han, X. Y.; Zhu, H. L. Polyhedron 2010, 29, 911-919.

13. Jia, T. J.; Li, S. M.; Cao, W.; Li, L. C.; Zheng, X. J.; Yuan, D. Q. J. Solid State Chem. 2013, 201, $208-214$.

14. Feil-Jenkins, J. F.; Nash, K. L.; Rogers, R. D. Inorg. Chim. Acta 1995, 236, 67-74.

15. Morss, L. R.; Nash, K. L.; Ensor, D. D. J. Chem. Soc., Dalton Trans. 2000, 285-291. 
16. Nash, K. L.; Horwitz, E. P.; Diamond, H.; Rickert, P. G.; Muntean, J. V.; Mendoza, M. D.; di Giuseppe, G. Solv. Extr. Ion Exch. 1996, 14, 13-33.

17. Thuéry, P.; Villiers, C.; Jaud, J.; Ephritikhine, M.; Masci, B. J. Am. Chem. Soc. 2004, 126, 68386839.

18. Thuéry, P. CrystEngComm 2013, 15, 6533-6545.

19. Nash, K. L.; Horwitz, E. P. , Gatrone, R. C.; Rickert, P. G. J. Alloys Compds. 1992, 180, 375-381.

20. Wang, J.; Zheng, L. L.; Li, C. J.; Zheng, Y. Z.; Tong, M. L. Cryst. Growth Des. 2006, 6, 357-359.

21.Thuéry, P.; Masci, B. Cryst. Growth Des. 2008, 8, 3430-3436.

22.Thuéry, P.; Masci, B. Cryst. Growth Des. 2010, 10, 3626-3631.

23. Thuéry, P. Eur. J. Inorg. Chem. 2013, 4563-4573.

24. Thuéry, P. CrystEngComm 2014, 16, 1724-1734.

25. Thuéry, P.; Harrowfield, J. Polyhedron 2015, 98, 5-11.

26. Lehn, J. M. Angew. Chem. Int. Ed. 2015, 54, 3276-3289.

27. Wang, K. X.; Chen, J. S. Acc. Chem. Res. 2011, 44, 531-540.

28. Chen, W.; Yuan, H. M.; Wang, J. Y.; Liu, Z. Y.; Xu, J. J.; Yang, M.; Chen, J. S. J. Am. Chem. Soc. 2003, 125, 9266-9267.

29. Frisch, M.; Cahill, C. L. Dalton Trans. 2006, 4679-4690.

30. Thuéry, P. Polyhedron 2007, 26, 101-106.

31. Alsobrook, A. N.; Hauser, B. G.; Hupp, J. T.; Alekseev, E. V.; Depmeier, W.; Albrecht-Schmitt, T. E. Cryst. Growth Des. 2011, 11, 1385-1393.

32. Mihalcea, I.; Volkringer, C.; Henry, N.; Loiseau, T. Inorg. Chem. 2012, 51, 9610-9618.

33. Cantos, P. M.; Pope, S. J. A.; Cahill, C. L. CrystEngComm 2013, 15, 9039-9051.

34. Thuéry, P.; Rivière, E. Dalton Trans. 2013, 42, 10551-10558. 
35. Cole, E.; Flores, E.; Basile, M.; Jayasinghe, A.; de Groot, J.; Unruh, D. K.; Forbes, T. Z. Polyhedron 2016, 114, 378-384.

36. Cahill, C. L.; de Lill, D. T.; Frisch, M. CrystEngComm 2007, 9, 15-26.

37. Andrews, M. B.; Cahill, C. L. Chem. Rev. 2013, 113, 1121-1136.

38. Loiseau, T.; Mihalcea, I.; Henry, N.; Volkringer, C. Coord. Chem. Rev. 2014, 266-267, 69-109.

39. Su, J.; Chen, J. S. Struct. Bond. 2015, 163, 265-296.

40. Thuéry, P.; Harrowfield, J. Inorg. Chem. 2016, 55, 6799-6816.

41. Hooft, R. W. W. COLLECT, Nonius BV: Delft, The Netherlands, 1998.

42. Otwinowski, Z.; Minor, W. Methods Enzymol. 1997, 276, 307-326.

43. Sheldrick, G. M. Acta Crystallogr., Sect. A 2015, 71, 3-8.

44. Sheldrick, G. M. Acta Crystallogr., Sect. C 2015, 71, 3-8.

45. Spek, A. L. J. Appl. Crystallogr. 2003, 36, 7-13.

46. Farrugia, L. J. J. Appl. Crystallogr. 1997, 30, 565.

47. Momma, K.; Izumi, F. J. Appl. Crystallogr. 2008, 41, 653-658.

48. Blatov, V. A.; Shevchenko, A. P.; Serezhkin V. N. J. Appl. Crystallogr. 2000, 33, 1193.

49. Leenheer, J. A.; Wershaw, R. L.; Reddy, M. M. Environ. Sci. Technol. 1995, 29, 399-405.

50. Villiers, C.; Thuéry, P.; Ephritikhine, M. Acta Crystallogr., Sect. E 2006, 62, o1724-o1726.

51. Bombieri, G.; Graziani, R.; Forsellini, E. Inorg. Nucl. Chem. Lett. 1973, 9, 551-557.

52. Jiang, J.; Sarsfield, M. J.; Renshaw, J. C.; Livens, F. R.; Collison, D.; Charnock, J. M.; Helliwell, M.; Eccles, H. Inorg. Chem. 2002, 41, 2799-2806.

53. Tian, G.; Rao, L.; Teat, S. J.; Liu, G. Chem. -Eur. J. 2009, 15, 4172-4181.

54. Lennartson, A.; Håkansson, M. Acta Crystallogr., Sect. C 2010, 66, m69-m74.

55. Allen, F. H. Acta Crystallogr., Sect. B 2002, 58, 380-388. 
56. Bruno, I. J.; Cole, J. C.; Edgington, P. R.; Kessler, M.; Macrae, C. F.; McCabe, P.; Pearson, J.; Taylor, R. Acta Crystallogr., Sect. B 2002, 58, 389-397.

57. Adelani, P. O.; Albrecht-Schmitt, T. E. Angew. Chem. Int. Ed. 2010, 49, 8909-8911.

58. Adelani, P. O.; Albrecht-Schmitt, T. E. Cryst. Growth Des. 2012, 12, 5800-5805.

59. Nelson, A. G. D.; Rak, Z.; Albrecht-Schmitt, T. E.; Becker, U.; Ewing, R. C. Inorg. Chem. 2014, $53,2787-2796$.

60. Shimoni-Livny, L.; Glusker, J. P.; Bock, C. W. Inorg. Chem. 1998, 37, 1853-1867.

61. Hancock, R. D.; Reibenspies, J. H.; Maumela, H. Inorg. Chem. 2004, 43, 2981-2987.

62. Harrowfield, J. Helv. Chim. Acta 2005, 88, 2430-2432.

63. Volkringer, C.; Henry, N.; Grandjean, S.; Loiseau, T. J. Am. Chem. Soc. 2012, 134, 1275-1283.

64. Knope, K. E.; de Lill, D. T.; Rowland, C. E.; Cantos, P. M.; de Bettencourt-Dias, A.; Cahill, C. L. Inorg. Chem. 2012, 51, 201-206.

65. Brachmann, A.; Geipel, G.; Bernhard, G.; Nitsche, H. Radiochim. Acta 2002, 90, 147-153.

66. Thuéry, P.; Harrowfield, J. CrystEngComm 2016, 18, 1550-1562.

67. Thuéry, P.; Masci, B.; Harrowfield, J. Cryst. Growth Des. 2013, 13, 3216-3224.

68. Thuéry, P.; Harrowfield, J. Inorg. Chem. 2015, 54, 6296-6305.

69. Zhang, Y.; Karatchevtseva, I.; Bhadbhade, M.; Tran, T. T.; Aharonovich, I.; Fanna, D. J.; Shepherd, N. D.; Lu, K.; Li, F.; Lumpkin, G. R. J. Solid State Chem. 2016, 234, 22-28.

70. Thuéry, P.; Harrowfield, J. Cryst. Growth Des. 2014, 14, 1314-1323.

71. Thuéry, P.; Harrowfield, J. Cryst. Growth Des. 2014, 14, 4214-4225.

72. Thuéry, P.; Rivière, E.; Harrowfield, J. Inorg. Chem. 2015, 54, 2838-2850.

73. Thuéry, P.; Harrowfield, J. CrystEngComm 2015, 17, 4006-4018.

74. Thuéry, P.; Harrowfield, J. Inorg. Chem. 2016, 55, 2133-2145.

75. Thuéry, P.; Rivière, E.; Harrowfield, J. Cryst. Growth Des. 2016, 16, 2826-2835. 
76. Thuéry, P.; Harrowfield, J. CrystEngComm 2016, 18, 3905-3918.

77. Thuéry, P.; Harrowfield, J. Inorg. Chem. 2015, 54, 8093-8102.

78. Redmond, M. P.; Cornet, S. M.; Woodall, S. D.; Whittaker, D.; Collison, D.; Helliwell, M.;

Natrajan, L. S. Dalton Trans. 2011, 40, 3914-3926.

79. Carter, K. P.; Kalaj, M.; Cahill, C. L. Eur. J. Inorg. Chem. 2016, 126-137.

80. Kerr, A. T.; Cahill, C. L. Cryst. Growth Des. 2014, 14, 1914-1921.

81. Luo, G. G.; Lin, L. R.; Huang, R. B.; Zheng, L. S. Dalton Trans. 2007, 3868-3870.

82. Yu, Y.; Zhan, W.; Albrecht-Schmitt, T. E. Inorg. Chem. 2007, 46, 10214-10220.

Table 1. Crystal Data and Structure Refinement Details

\begin{tabular}{|c|c|c|c|c|c|c|c|}
\hline & 1 & 2 & 3 & 4 & 5 & 6 & 7 \\
\hline chemical formula & $\mathrm{C}_{18} \mathrm{H}_{24} \mathrm{~N}_{6} \mathrm{O}_{20} \mathrm{U}$ & $\mathrm{C}_{20} \mathrm{H}_{20} \mathrm{~N}_{2} \mathrm{O}_{26} \mathrm{U}_{3}$ & $\mathrm{C}_{16} \mathrm{H}_{16} \mathrm{Ag}_{2} \mathrm{O}_{28} \mathrm{U}_{3}$ & $\mathrm{C}_{8} \mathrm{H}_{6} \mathrm{O}_{12} \mathrm{PbU}$ & $\mathrm{C}_{8} \mathrm{H}_{10} \mathrm{O}_{14} \mathrm{PbU}$ & $\mathrm{C}_{8} \mathrm{H}_{5} \mathrm{Ag}_{3} \mathrm{O}_{9}$ & $\mathrm{C}_{8} \mathrm{H}_{6} \mathrm{O}_{10} \mathrm{~Pb}_{2}$ \\
\hline cryst syst & triclinic & triclinic & triclinic & triclinic & triclinic & monoclinic & monoclinic \\
\hline space group & $P-1$ & $P-1$ & $P-1$ & $P-1$ & $P-1$ & $C 2 / c$ & $P 2_{1} / c$ \\
\hline$a(\AA)$ & $6.2002(3)$ & $8.7169(7)$ & $8.7147(5)$ & $8.8187(7)$ & $8.8496(7)$ & $23.2795(14)$ & $7.4504(4)$ \\
\hline$b(\AA)$ & $10.6342(6)$ & $9.3205(7)$ & $10.2265(7)$ & $8.8607(7)$ & $9.0520(5)$ & $15.6544(10)$ & $14.8246(7)$ \\
\hline$\beta$ (deg) & $86.674(4)$ & $80.405(5)$ & $99.416(4)$ & $109.384(5)$ & $86.077(4)$ & $96.116(4)$ & $101.315(3)$ \\
\hline$\gamma(\operatorname{deg})$ & $78.118(4)$ & $82.241(5)$ & $110.693(4)$ & $103.226(4)$ & $71.439(5)$ & 90 & 90 \\
\hline$V\left(\breve{A}^{3}\right)$ & $668.31(7)$ & $807.48(11)$ & $746.80(9)$ & $599.47(9)$ & $709.75(10)$ & $2185.9(2)$ & $1069.54(8)$ \\
\hline$Z$ & 1 & 1 & 1 & 2 & 2 & 8 & 4 \\
\hline$D_{\text {calcd }}\left(\mathrm{g} \mathrm{cm}^{-3}\right)$ & 2.193 & 2.917 & 3.527 & 4.096 & 3.628 & 3.456 & 4.201 \\
\hline$\mu(\mathrm{Mo} \mathrm{K} \alpha)\left(\mathrm{mm}^{-1}\right)$ & 6.178 & 15.112 & 17.612 & 27.586 & 23.319 & 5.368 & 31.498 \\
\hline params refined & 205 & 233 & 223 & 199 & 217 & 191 & 181 \\
\hline$R_{1}$ & 0.028 & 0.027 & 0.029 & 0.047 & 0.027 & 0.048 & 0.025 \\
\hline$w R_{2}$ & 0.072 & 0.055 & 0.071 & 0.134 & 0.055 & 0.129 & 0.065 \\
\hline$S$ & 1.051 & 1.024 & 1.059 & 1.109 & 1.063 & 1.043 & 1.129 \\
\hline$\Delta \rho_{\min }\left(\mathrm{e} \AA^{-3}\right)$ & -1.48 & -1.61 & -2.01 & -2.46 & -2.05 & -3.41 & -2.53 \\
\hline$\Delta \rho_{\max }\left(\mathrm{e} \AA^{-3}\right)$ & 1.01 & 1.40 & 2.13 & 2.80 & 1.20 & 2.08 & 1.08 \\
\hline
\end{tabular}




\section{Figure Captions}

Figure 1. Top: View of complex 1. Displacement ellipsoids are drawn at the $50 \%$ probability level. Symmetry code: $\mathrm{i}=-x, 1-y, 1-z$. Bottom: View of a hydrogen bonded sheet, with uranium coordination polyhedra colored yellow. The carbon-bound hydrogen atoms are omitted and hydrogen bonds are shown as dashed lines in both views.

Figure 2. Top left: View of complex 2. Displacement ellipsoids are drawn at the $50 \%$ probability level. The solvent molecule and carbon-bound hydrogen atoms are omitted. The hydrogen bond is shown as a dashed line. Symmetry codes: $\mathrm{i}=1-x, 2-y, 2-z ; \mathrm{j}=x, y, z-1 ; \mathrm{k}=2-x, 1-y, 2-$ $z ; 1=x, y, z+1$. Top right: View of the $2 \mathrm{D}$ assembly with the uranium coordination polyhedra colored yellow. Bottom left: Packing with layers viewed edge-on. All hydrogen atoms are omitted in the last two views. Bottom right: Nodal representation of the 2D network (yellow: uranium, red: oxygen, blue: ligand centroid).

Figure 3. Top: View of complex 3. Displacement ellipsoids are drawn at the $50 \%$ probability level. The solvent molecules and carbon-bound hydrogen atoms are omitted. Symmetry codes: $\mathrm{i}=x-1$, $y-1, z ; \mathrm{j}=1-x, 1-y, 2-z ; \mathrm{k}=2-x, 1-y, 1-z ; 1=x-1, y, z ; \mathrm{m}=1-x, 2-y, 2-z ; \mathrm{n}=x+1$, $y, z ; \mathrm{o}=x+1, y+1, z ; \mathrm{p}=1-x, 1-y, 1-z$. Bottom: View of the 3D framework with uranium coordination polyhedra colored yellow and silver atoms shown as blue spheres. The uraniumcontaining layers are similar to those in complex 2. Solvent molecules and hydrogen atoms are omitted. 
Figure 4. Top: View of complex 4. Displacement ellipsoids are drawn at the 50\% probability level. Carbon-bound hydrogen atoms are omitted. Symmetry codes: $\mathrm{i}=x, y, z+1 ; \mathrm{j}=-x, 1-y, 2-z ; \mathrm{k}$ $=1-x,-y, 2-z ; 1=1-x,-y, 1-z ; \mathrm{m}=x, y-1, z ; \mathrm{n}=x, y, z-1 ; \mathrm{o}=x, y+1, z$. Middle and bottom: Two views of the 3D framework with uranium coordination polyhedra colored yellow and lead atoms shown as blue spheres. All hydrogen atoms are omitted in the last two views.

Figure 5. Top: View of complex 5. Displacement ellipsoids are drawn at the 50\% probability level. The solvent molecule and carbon-bound hydrogen atoms are omitted. Symmetry codes: $\mathrm{i}=x, y, z$ $-1 ; \mathrm{j}=1-x, 1-y, 1-z ; \mathrm{k}=2-x, 2-y, 1-z ; 1=1-x, 2-y, 1-z ; \mathrm{m}=x, y+1, z ; \mathrm{n}=x, y, z+$ $1 ; \mathrm{o}=x, y-1, z$. Bottom: View of the 3D framework with uranium coordination polyhedra colored yellow and lead atoms shown as blue spheres. Solvent molecules and hydrogen atoms are omitted.

Figure 6. Top: View of the silver-only complex 6. Displacement ellipsoids are drawn at the $40 \%$ probability level. Carbon-bound hydrogen atoms are omitted. Symmetry codes: $\mathrm{i}=x, y, z-1 ; \mathrm{j}=$ $1-x, y, 1 / 2-z ; \mathrm{k}=x,-y, z-1 / 2 ; 1=1 / 2-x, 1 / 2-y,-z ; \mathrm{m}=1-x, 1-y,-z ; \mathrm{n}=x, 1-y, z-1 / 2 ;$ $\mathrm{o}=x, 1-y, z+1 / 2 ; \mathrm{p}=x,-y, z+1 / 2 ; \mathrm{q}=x, y, z+1$. Middle and bottom: Two views of the 3D framework with all hydrogen atoms omitted. In all views, only one position (and its symmetry equivalents) of the disordered silver cation Ag3 is represented.

Figure 7. Top: View of the lead-only complex 7. Displacement ellipsoids are drawn at the 50\% probability level. Carbon-bound hydrogen atoms are omitted. Symmetry codes: $\mathrm{i}=-x, y+1 / 2,3 / 2$ $-z ; \mathrm{j}=1-x, y+1 / 2,3 / 2-z ; \mathrm{k}=x, 1 / 2-y, z+1 / 2 ; 1=-x, 1-y, 2-z ; \mathrm{m}=1-x, 1-y, 1-z ; \mathrm{n}=$ $x+1, y, z ; \mathrm{o}=x, 1 / 2-y, z-1 / 2 ; \mathrm{p}=x-1, y, z ; \mathrm{q}=1-x, y-1 / 2,3 / 2-z ; \mathrm{r}=-x, y-1 / 2,3 / 2-z$. Bottom: View of the 3D framework with all hydrogen atoms omitted. 
Figure 8. Solid state emission spectra of the homometallic uranyl complexes $\mathbf{1}$ and $\mathbf{2}$ and the uranyl/lead(II) heterometallic complex 4 (top), and of the heterometallic complexes $\mathbf{3}$ and $\mathbf{5}$ (bottom). The excitation wavelength was $420 \mathrm{~nm}$.

Scheme 1. Coordination Mode of the thftc Ligand in the Polymeric Complexes 2-7

2

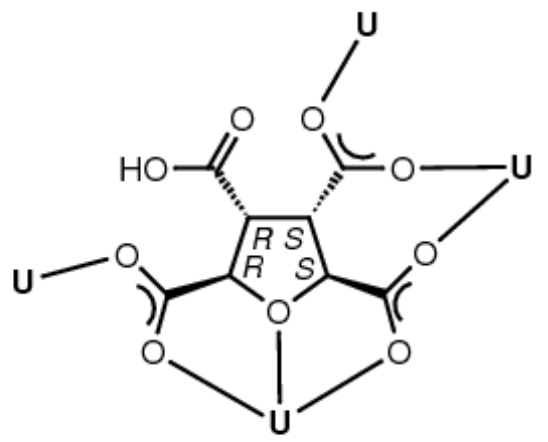

4

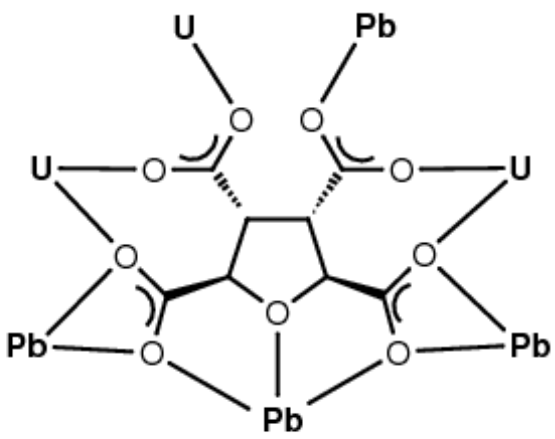

6

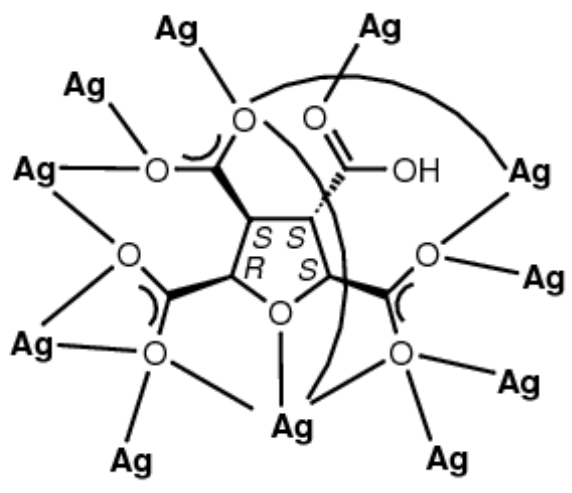

3

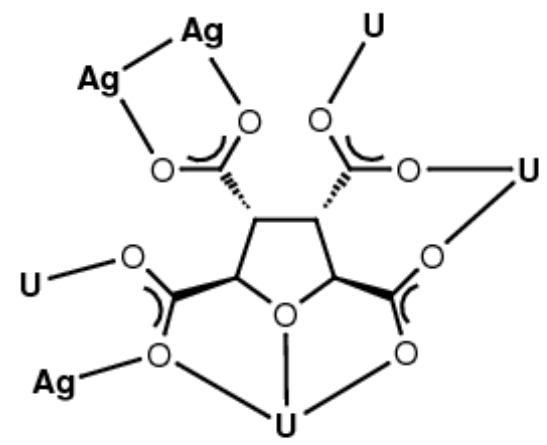

5

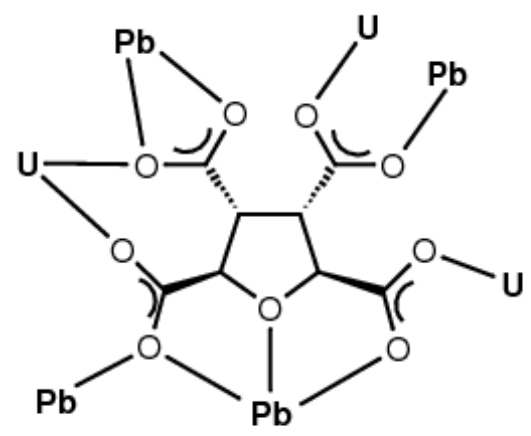

7

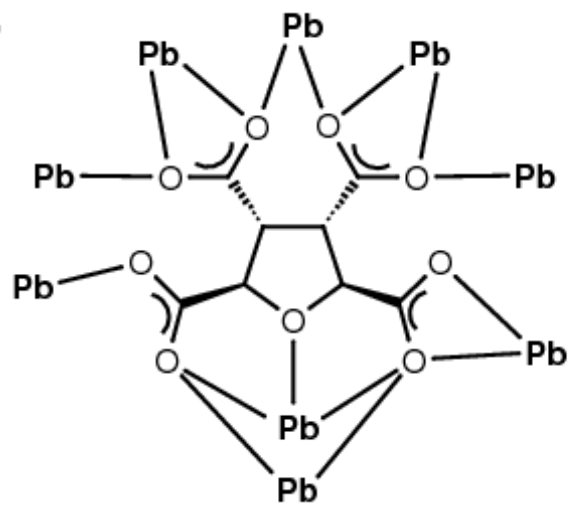


Figure 1
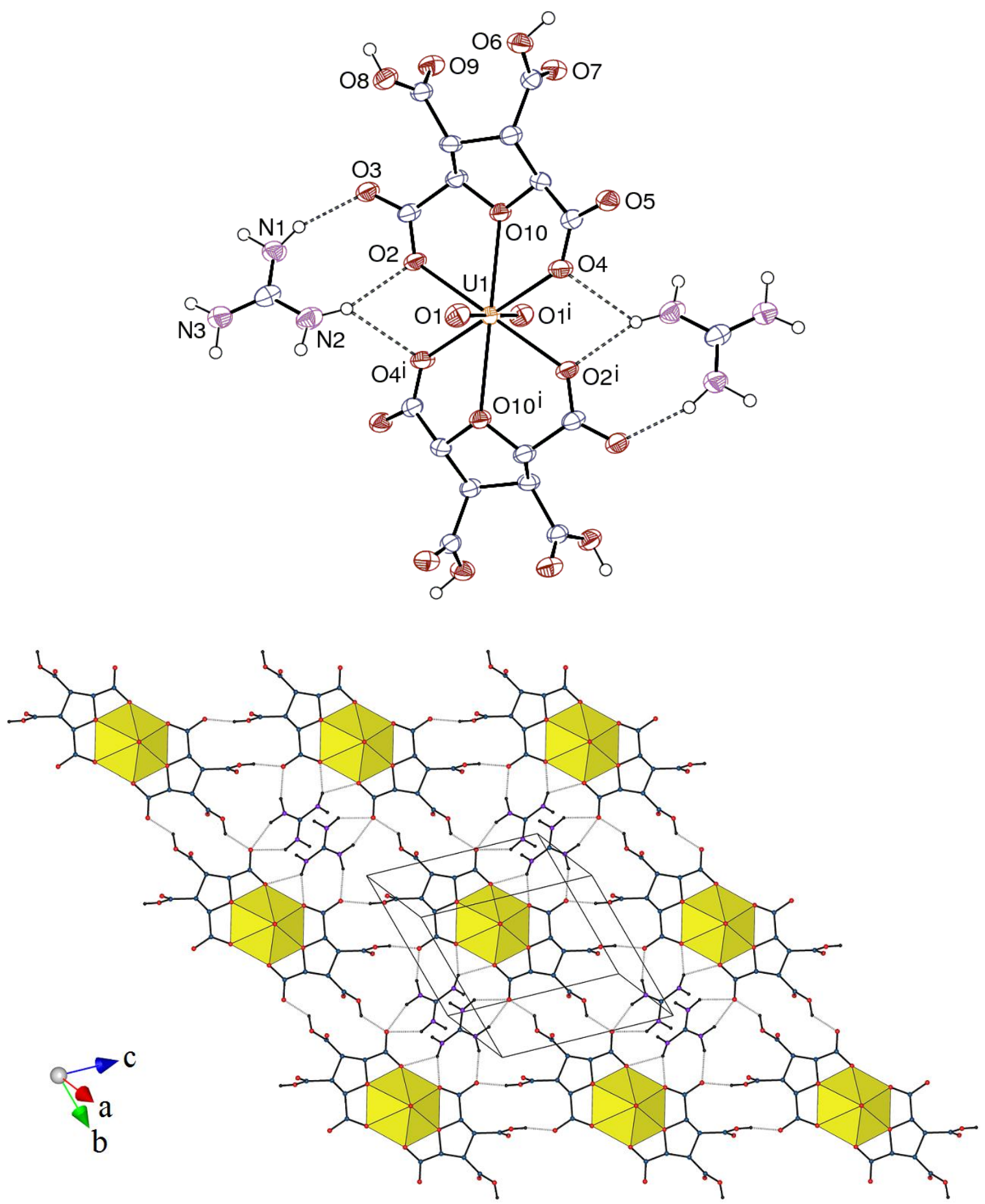
Figure 2
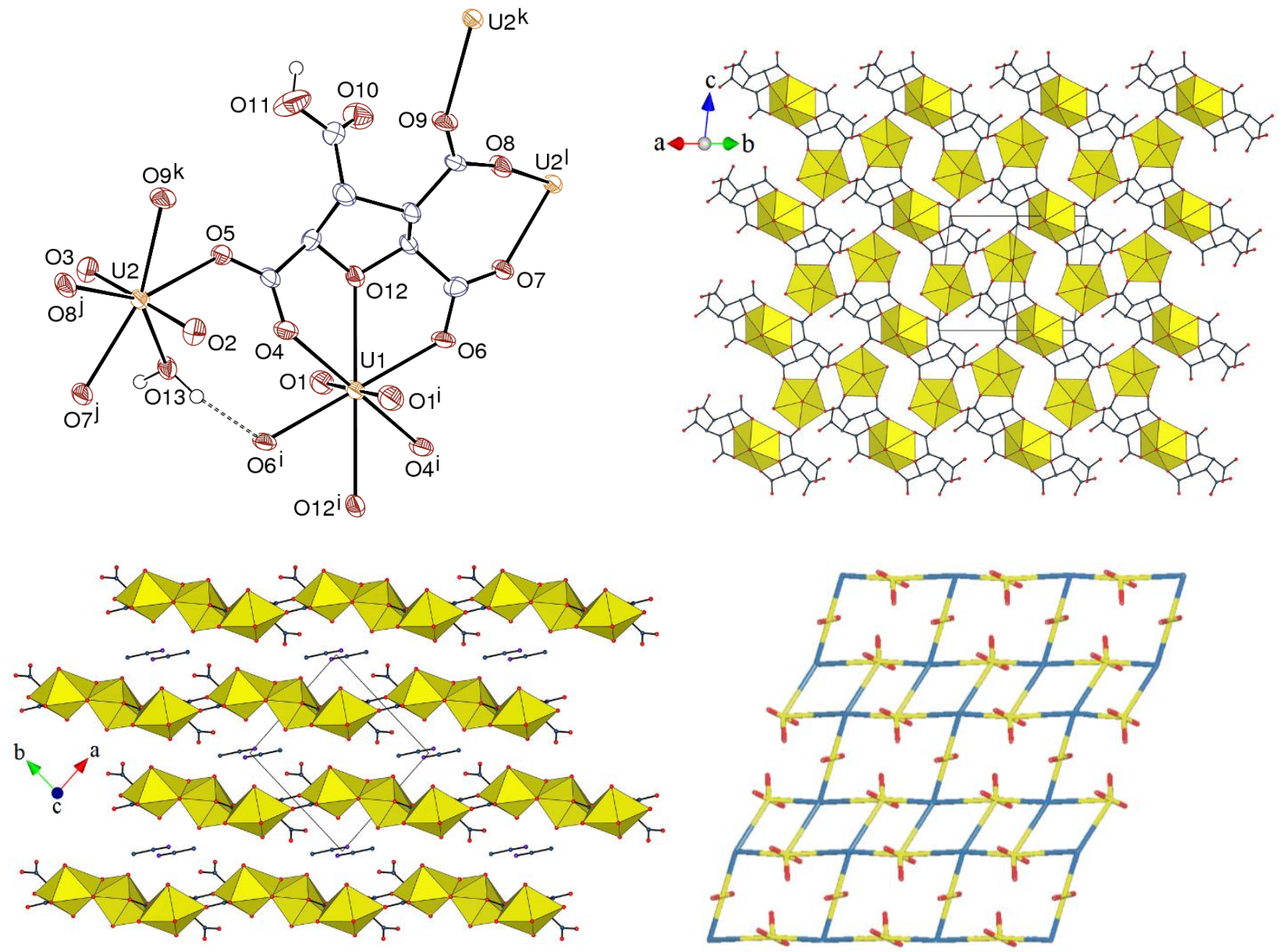
Figure 3
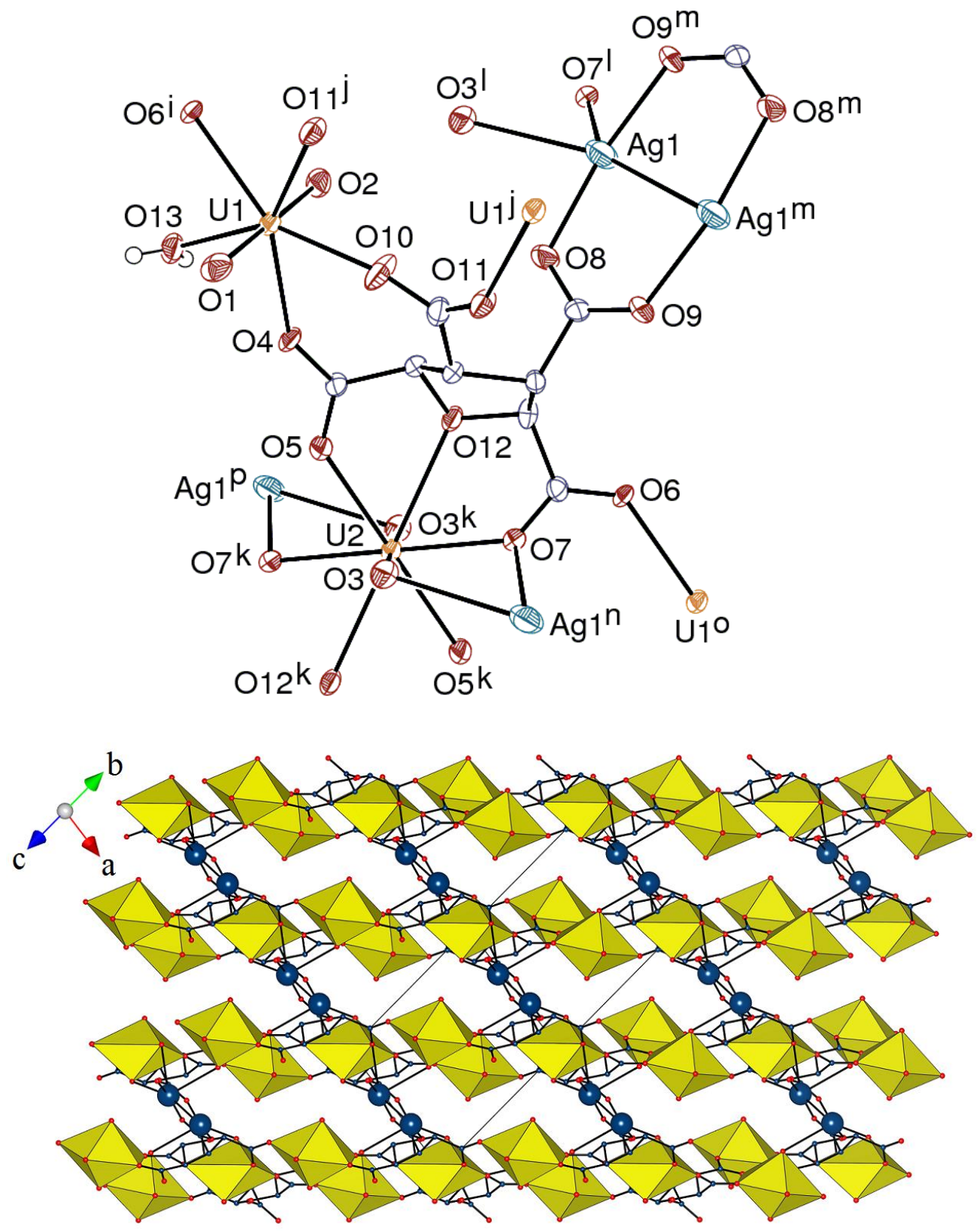
Figure 4
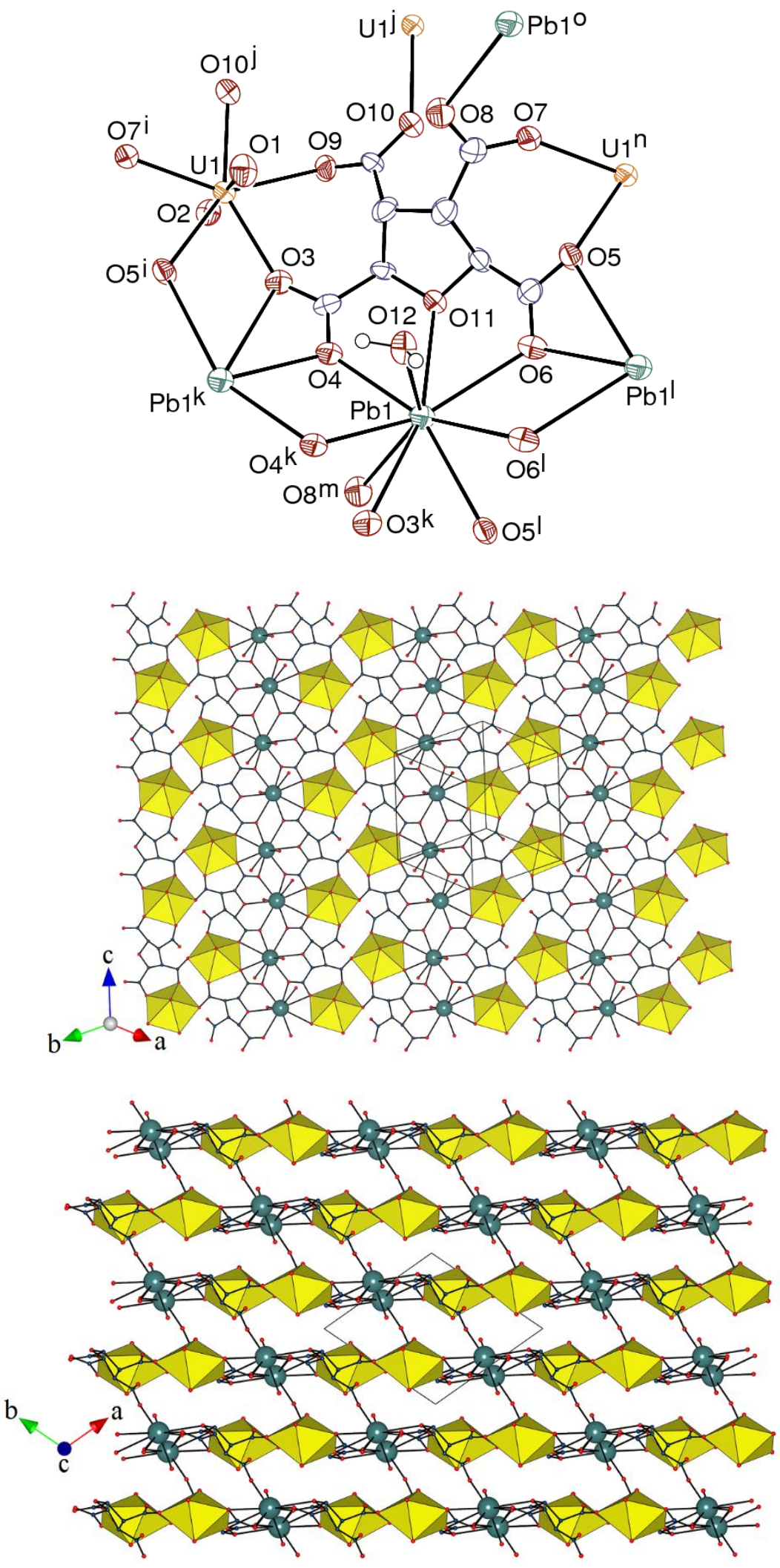
Figure 5
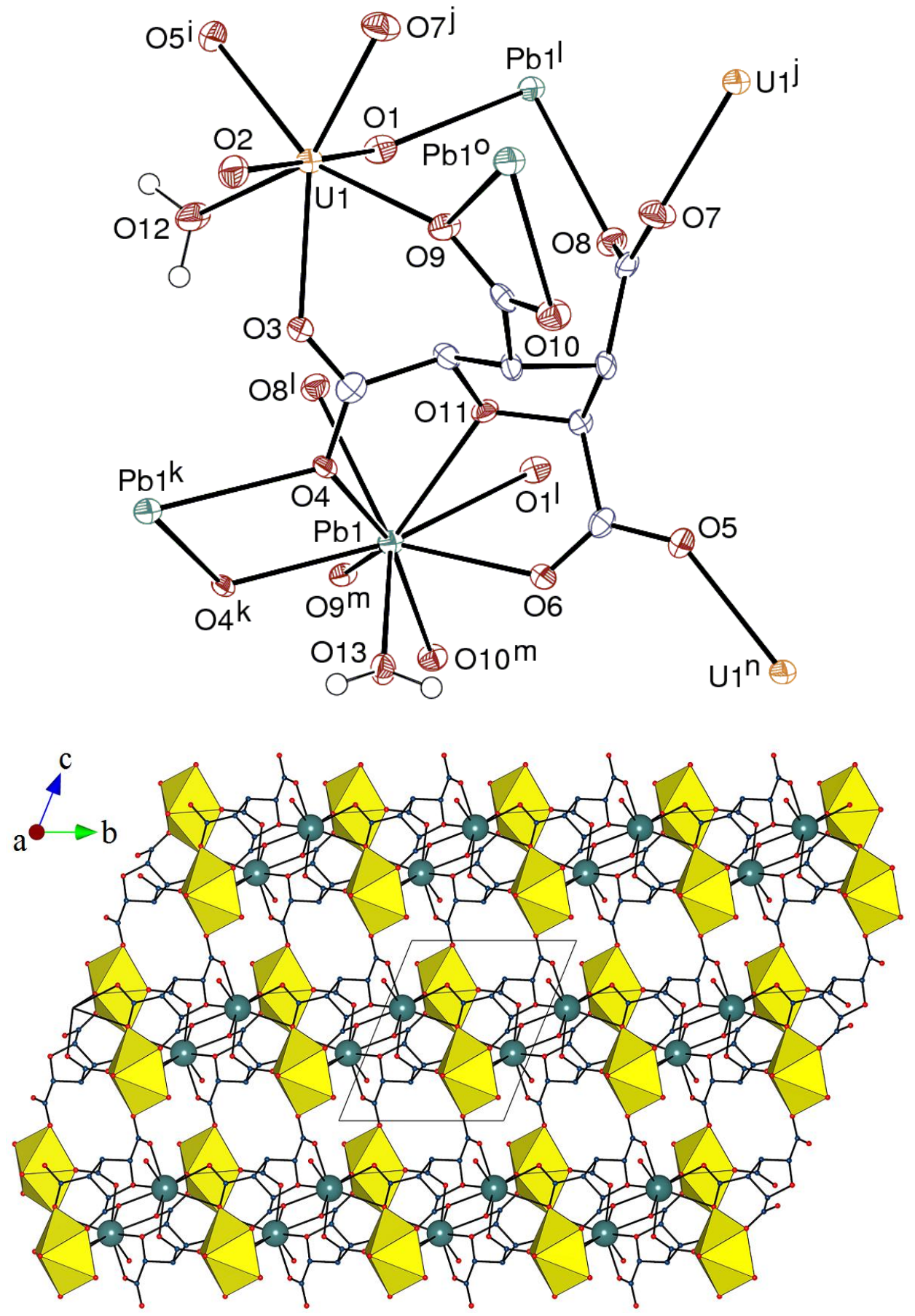
Figure 6
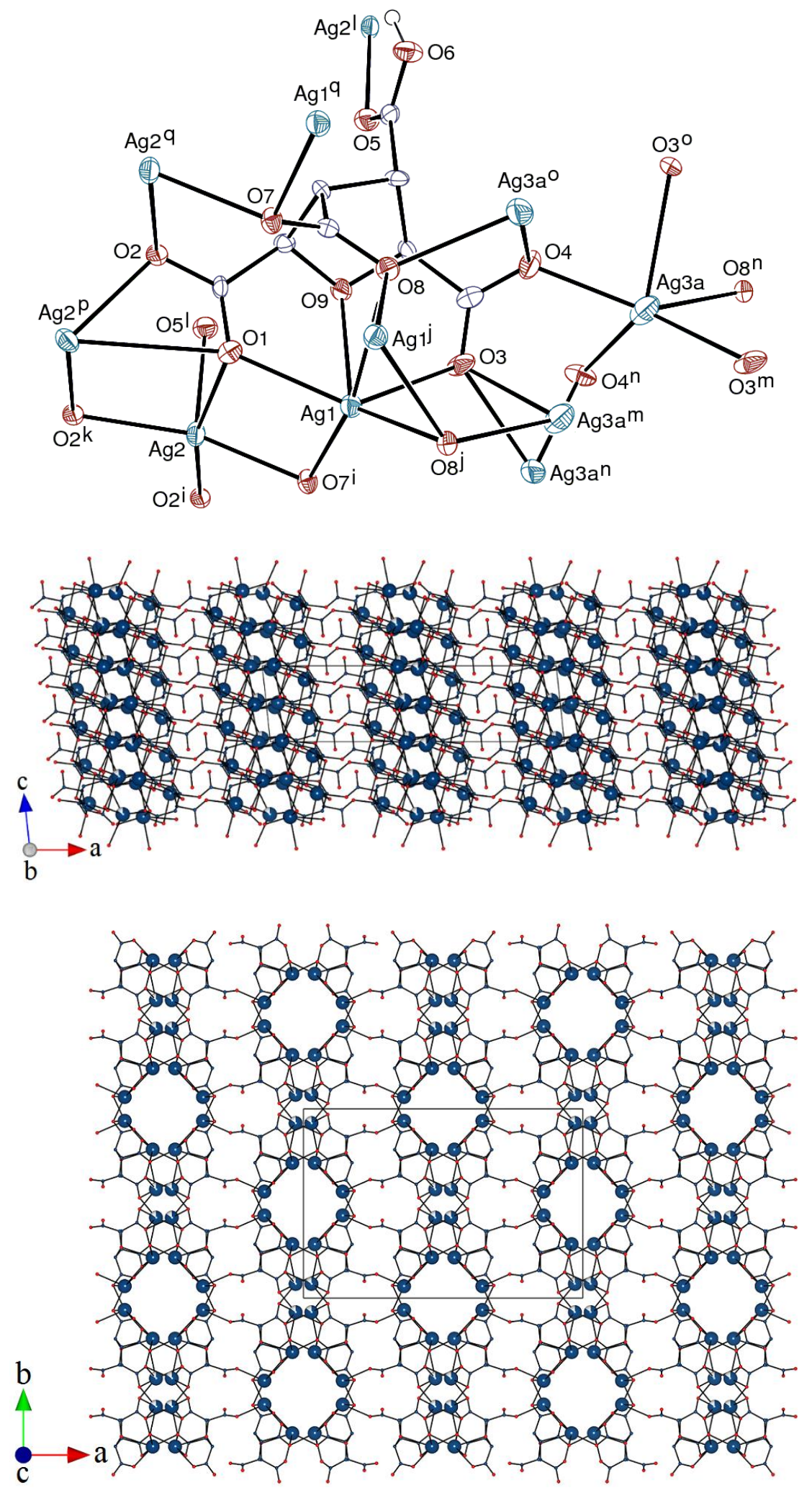
Figure 7
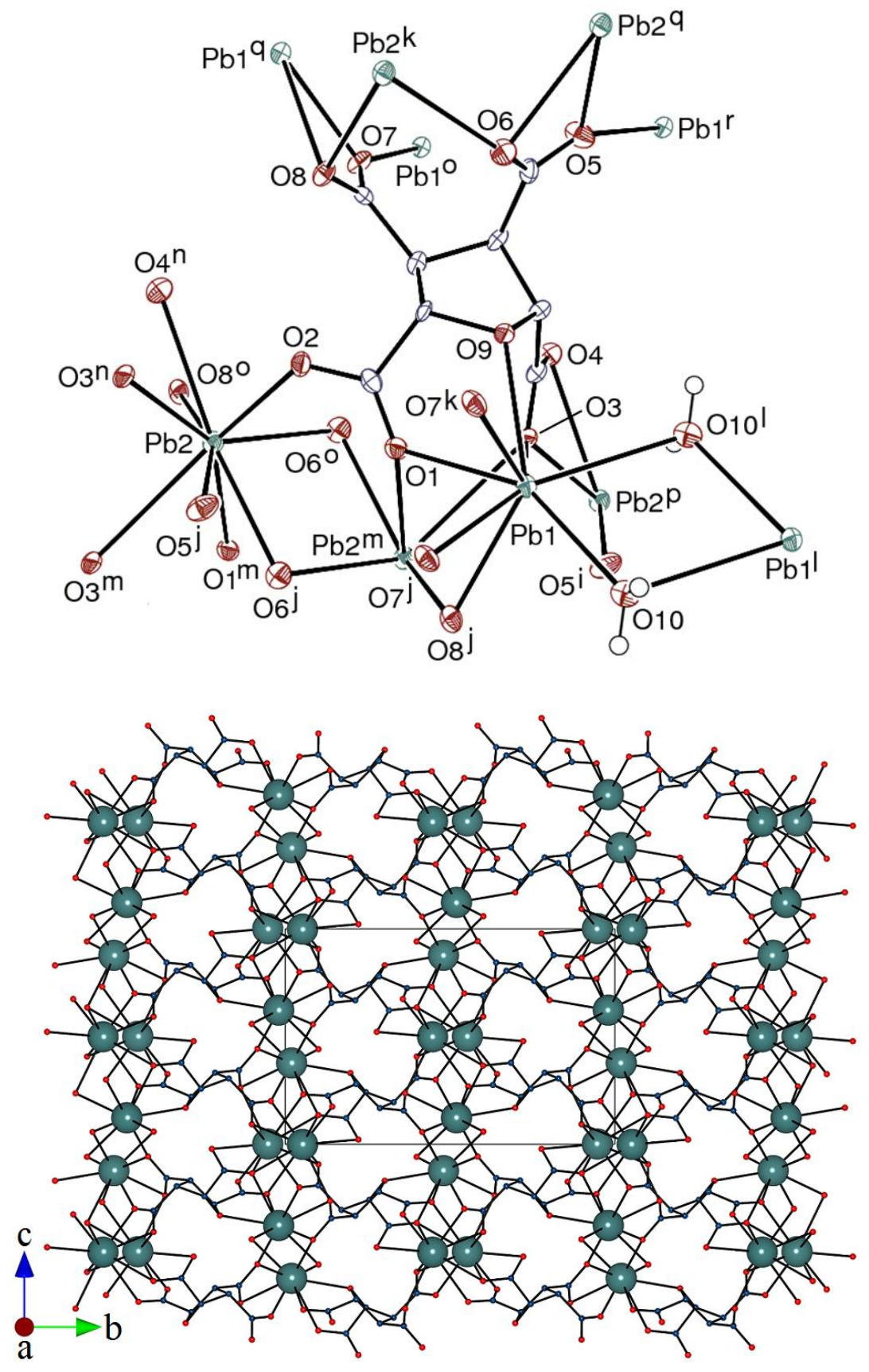
Figure 8
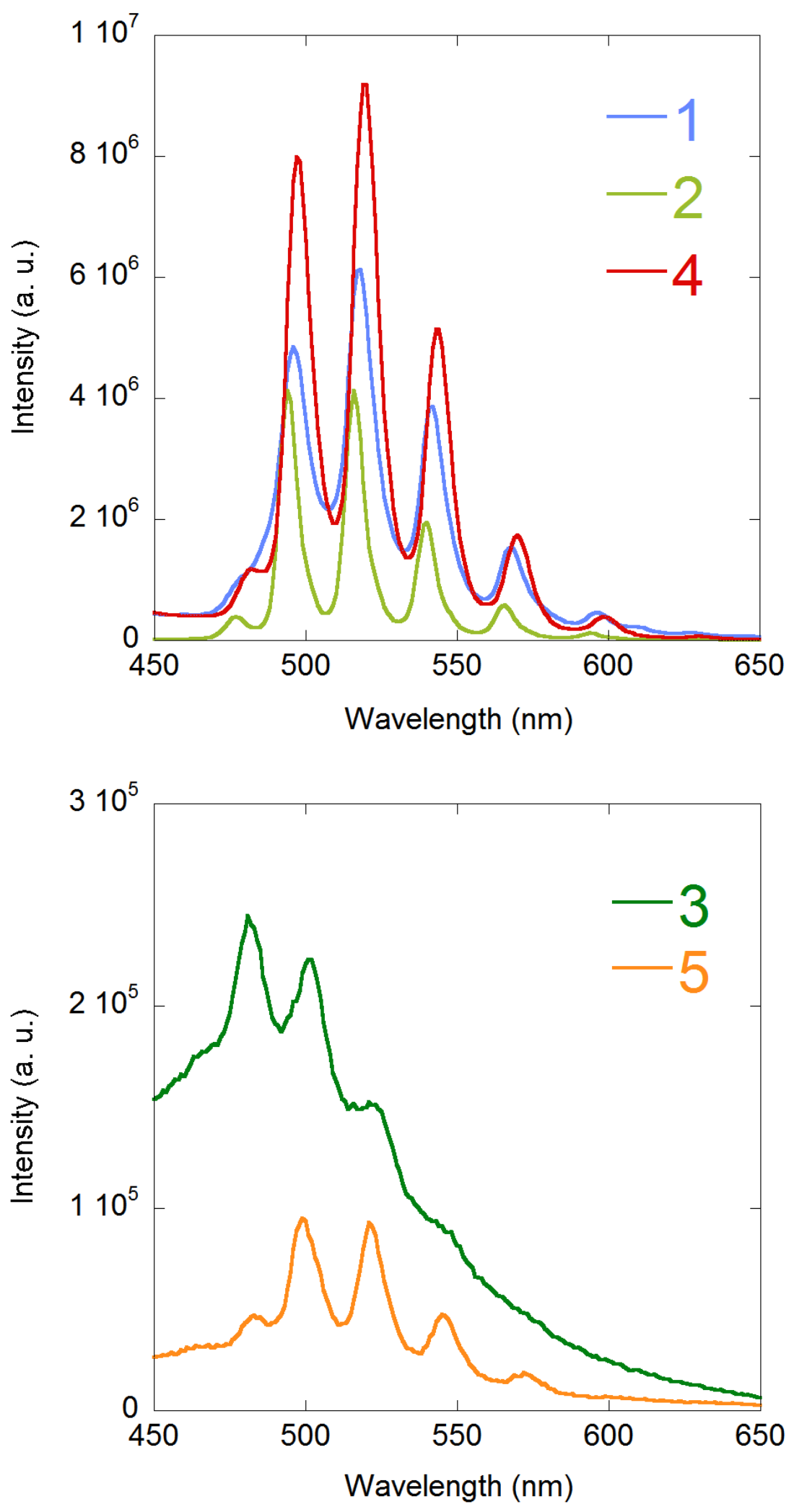


\section{For Table of Contents Use Only}

\section{Tetrahydrofurantetracarboxylic Acid: an Isomerizable Framework-Forming Ligand in Homo- and Heterometallic Complexes with $\mathrm{UO}_{2}{ }^{2+}, \mathrm{Ag}^{+}$and $\mathrm{Pb}^{2+}$}

Pierre Thuéry and Jack Harrowfield

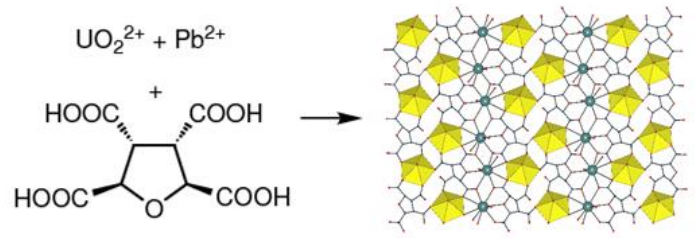

Seven homo- and heterometallic complexes formed by tetrahydrofurantetracarboxylic acid with either uranyl, silver(I) or lead(II) cations or mixtures thereof display arrangements of various dimensionality, among which three-dimensional frameworks are dominant. The ligand is found to have undergone isomerization into one of its chiral forms in the silver-only complex. 